\title{
Republic of Lithuania: Selected Issues Paper
}

This Selected Issues Paper for the Republic of Lithuania was prepared by a staff team of the International Monetary Fund as background document for the periodic consultation with the member country. It is based on the information available at the time it was completed on November 2, 2011. The views expressed in this document are those of the staff team and do not necessarily reflect the views of the government of the Republic of Lithuania or the Executive Board of the IMF.

The policy of publication of staff reports and other documents allows for the deletion of market-sensitive information.

Copies of this report are available to the public from

International Monetary Fund $\bullet$ Publication Services

$70019^{\text {th }}$ Street, N.W. $\bullet$ Washington, D.C. 20431

Telephone: (202) 623-7430 • Telefax: (202) 623-7201

E-mail: publications@imf.org Internet: http://www.imf.org

\section{International Monetary Fund Washington, D.C.}




\section{INTERNATIONAL MONETARY FUND}

\section{REPUBLIC OF LITHUANIA}

\section{Selected Issues}

Prepared by Jeta Menkulasi, Jacques Miniane (both EUR), and Tigran Poghosyan (FAD) Approved by the European Department

November 2, 2011

\section{Contents}

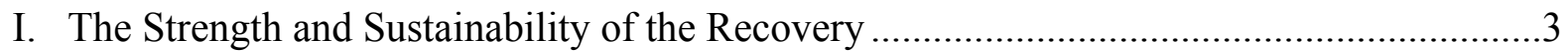
A. The Boom and the Bust. 3
B. What Determines the Strength of the Recovery: A Model-Based Approach ...........5

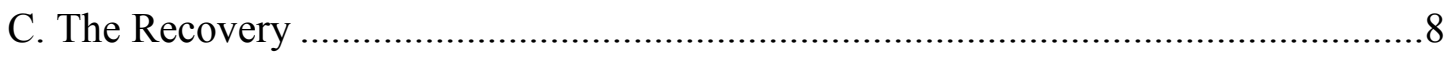

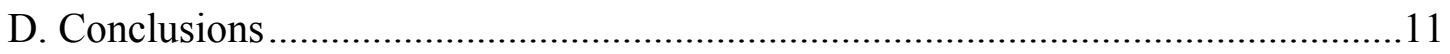

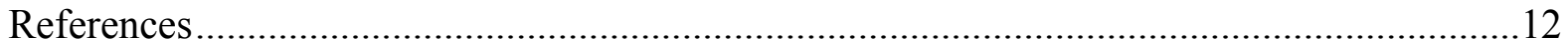

Appendix

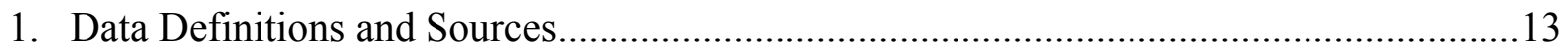

II. How Fast Can The Baltics Grow In The Medium Term? .............................................. 14

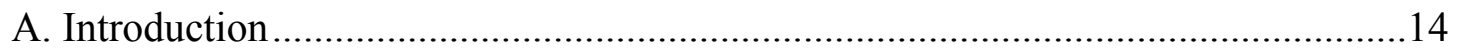

B. Medium-Term Growth Prospects .................................................................... 15

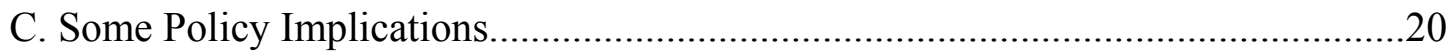

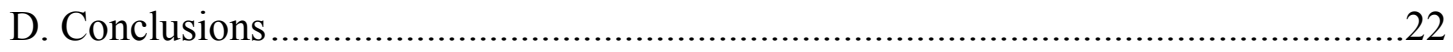

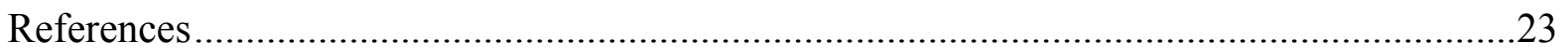

Appendix

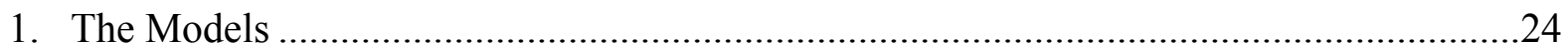


III. Assessing the Variability of Tax Elasticities in Lithuania........................................26

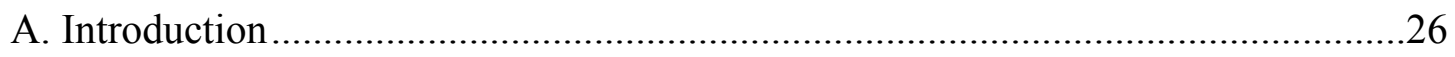

B. Related Literature on Estimating Tax Elasticities...............................................27

C. Brief Overview of the Lithuanian Tax System ...................................................28

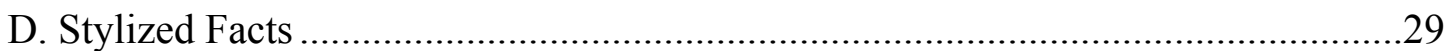

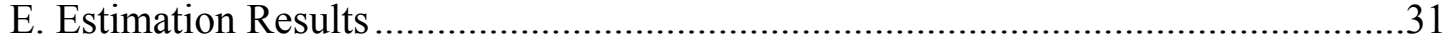

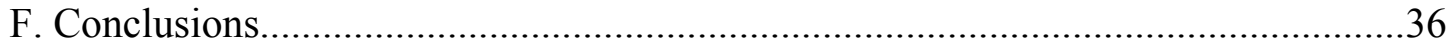

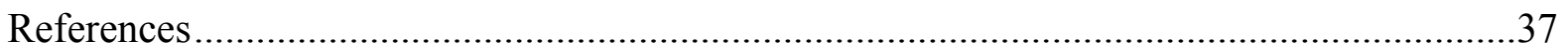

Appendix

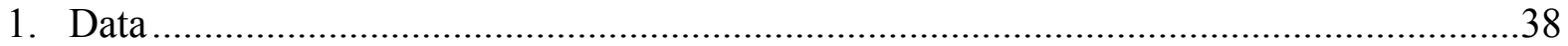




\section{The Strength And SuStainability OF THE ReCOVERY ${ }^{1}$}

In the run-up to the 2008-09 crisis, economic growth was characterized by a significant misallocation of resources towards non-tradable sectors, which led to unsustainable imbalances. During the crisis, the output contraction and internal price adjustments corrected much of these imbalances. This paper finds early signs of a rebalancing of economic activity towards tradable sectors, but this is not yet firmly entrenched.

\section{A. The Boom and the Bust}

\section{Non-tradable sectors accounted for more} than 75 percent of GDP growth in the Baltic countries during the pre-crisis boom. ${ }^{2}$ By contrast, in the CEE countries (Czech Republic, Hungary, Poland, Slovakia, and Slovenia) non-tradables were responsible on average for less than 50 percent of growth. Among the Baltic countries, Latvia stands out with more than 92 percent of growth due to non-tradables. While a small increase in the share of non-tradables in GDP could be the result of higher spending on services as income per capita rises, the speed of the shift was unduly fast in the Baltic countries and focused on only a few sectors like construction and real estate.

\section{The increase in the share of non-tradables} was fueled by credit growth and FDI flows. As foreign direct investment (FDI) inflows increased, they were being progressively allocated to sectors like financial intermediation and real estate. The share of FDI flows going to financial intermediation and real estate in GDP more than doubled between 2004-07 for all three Baltic countries, whereas the share of FDI flows going to manufacturing and agriculture declined. ${ }^{3}$ In Estonia and Latvia, the share

\footnotetext{
${ }^{1}$ Prepared by Jeta Menkulasi.

${ }^{2}$ For cross-country comparison, tradables are defined as manufacturing, agriculture, mining and quarrying. However, note that other sectors might have a significant tradable component depending on the country. ${ }^{3}$ FDI going to agriculture and manufacturing decreased by 30 percent in Estonia and Lithuania, whereas it increased by 75 percent in Latvia. However it must be noted that Latvia has the smallest share of FDI allocated to manufacturing as compared with the two other Baltic countries.
}

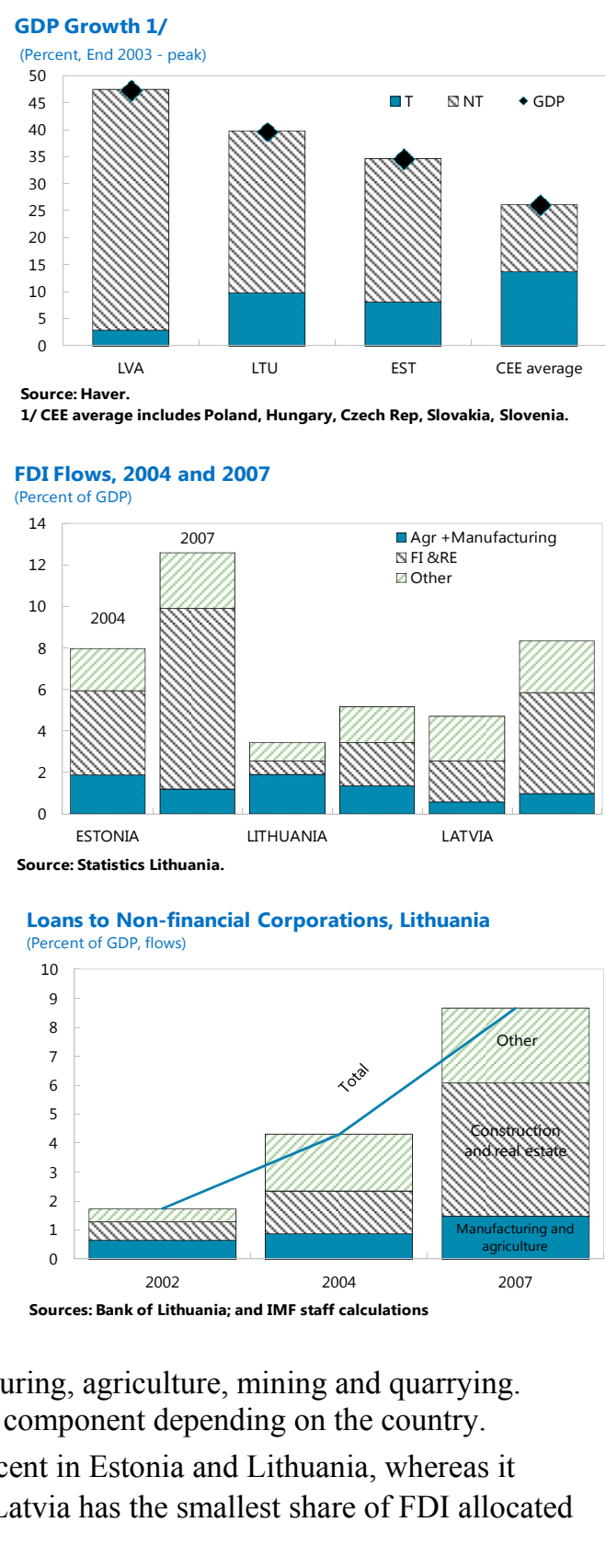


of FDI going to non-tradables increased in 2007 to 8.7 percent of GDP and 5 percent of GDP, respectively, whereas in Lithuania it was only 2.1 percent of GDP. In the Baltic countries, the share of private sector credit in GDP increased by 30 percentage points of GDP on average between 2004-07, much of which was directed to construction and real estate.

\section{Higher wages and higher unit labor costs (ULC) eroded competitiveness, held} back export growth, and resulted in a demand boom that boosted imports. The wage bill doubled in Lithuania between 2000-08, in line with the CEE average, whereas it tripled in Estonia and Latvia. However, the sectoral distribution of wage increases also matters. In Estonia and Lithuania, wage increases in non-tradables were not matched one-to-one by wage increases in tradables. In fact, cumulative wage increases in manufacturing were some 40 percent lower than in construction. In Latvia on the other hand the spillovers from nontradables to tradables were much larger, perhaps because of the smaller relative size of the latter.

Wages and Salaries $(2000 Q 1=100$, SA $)$
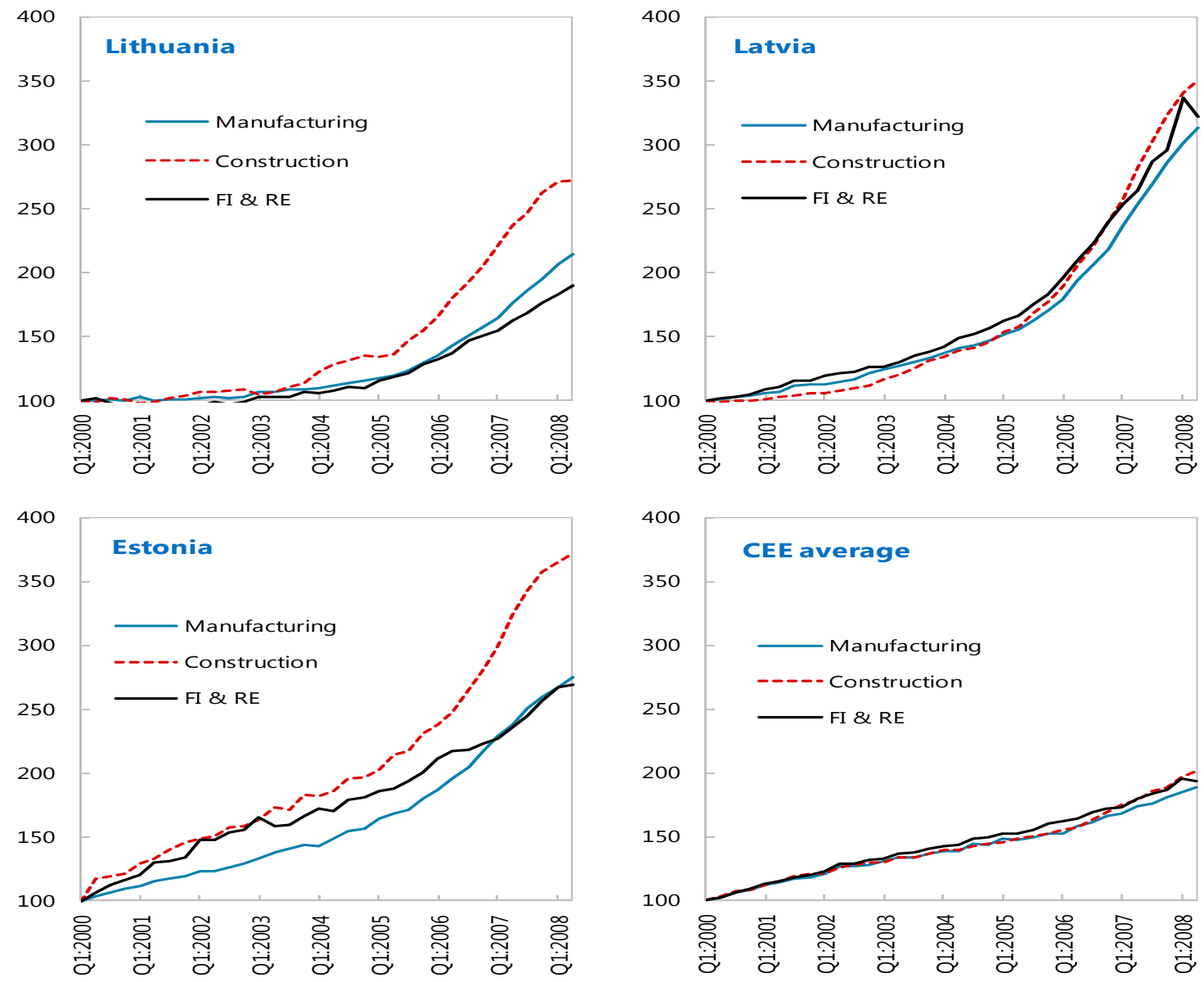

Source: Eurostat. 
4. Once external imbalances became unsustainable, countries with a higher share of non-tradables experienced a sharper contraction. In the Baltics, both tradables and non-tradables were affected by the combined shocks of collapsing global trade and the sudden stop in foreign funding. However, given that imbalances in real estate and construction were larger than in manufacturing, the relative price of nontradables fell sharply. In the CEE countries, where economic growth was led by tradable sectors, the contraction of global demand was the main cause of output contraction.

\section{B. What Determines the Strength of the Recovery: A Model-Based Approach}

\section{As economies recover from the crisis, what determines how strongly each} recovery is proceeding? In order to answer this question, we pursue a cross country empirical analysis to determine which variables have proven to be most relevant in explaining cumulative growth since the trough. We focus on the set of countries that have experienced a recession during the past crisis. This, combined with limited availability of quarterly data, limits our sample to 52 countries. The recovery is defined as the percent change in output from trough to the latest data point available and recession as the percent change in output from peak to trough ${ }^{4}$. Following Lane and Milesi-Ferretti (2010), Park and Lee (2001), Didier et al (2011), we consider the following explanatory variables: the magnitude of the recession, the pre-crisis current account balance as a share of GDP, the level of trade openness, the exchange rate regime, trading partner growth post-crisis, as well as the rate of credit growth before the crisis..$^{5}$ The first variable is intended to capture any bounce-back effects. However, it is also possible that sharp output contractions lead to permanently lower potential output as resources become permanently idle, implying a slow recovery. Variables like pre-crisis current account deficit and credit growth are meant to capture imbalances that led to the crisis and whether they have an effect on the strength of the recovery. Lastly, trade openness gauges the extent to which the recovery in global trade is transmitted into the domestic recovery.

\section{The sharper the recession, the smaller pre-crisis imbalances and the faster trading partner growth, the stronger the recovery.}

- $\quad$ Bounce back effect: Our empirical results show that there is a significant bounce-back effect. For each additional percentage point of total peak to trough contraction, cumulative growth since peak will be 0.46 percent higher. In this respect Baltic countries are likely to experience a stronger recovery than other CEE countries.

\footnotetext{
${ }^{4}$ Results are similar when growth per quarter is used as the right hand variable instead if cumulative recovery.

${ }^{5}$ To avoid endogeneity we use pre-recovery variables.
} 
- $\quad$ Pre-crisis imbalances: A high current account deficit before the crisis negatively affects the strength of the recovery. The coefficient is large and significant. This is particularly relevant for the Baltic countries, as the current account deficit in 2007 varied between 15 and 20 percent of GDP, compared to an average of 5 percent of GDP in the CEE countries. Credit growth preceding the crisis negatively and significantly affects the recovery. Between 2004 and 2007, the private credit to GDP ratio increased by 25 percentage points of GDP in Lithuania and by almost 40 percentage points of GDP in Latvia, compared to 13 percentage points of GDP in the $\mathrm{CEE}$ countries. As deleveraging and a heightened perception of risk are lowering the appetite for credit, this takes a toll on domestic demand and growth. Taking both variables into account, smaller pre-crisis imbalances in Lithuania than in Latvia and Estonia would increase the chances of a faster recovery relative to Baltic neighbors, though the recovery would be slower than in the rest of CEE countries like Slovakia, Czech Republic and Hungary.

- $\quad$ Trading partner growth: The recovery in trading partner growth has a strong and significant effect on growth. All three Baltic countries are facing comparable trading partner growth, and higher than the CEE average.

Baseline Specification (Dependent variable $=$ Recovery)

\begin{tabular}{lc}
\hline Regressors & Coefficient estimates \\
\hline Recession & $-0.46^{\star * *}$ \\
Log GDP/capita, 2007 & 0.14 \\
& $-2.52^{\star * *}$ \\
Current Account Balance, 2007 & 0.71 \\
& $0.29^{\star * *}$ \\
Trade Openness & 0.09 \\
& 0.002 \\
OIL & 0.01 \\
& -2.24 \\
Peg & 1.96 \\
Trading partner growth & -2.16 \\
& 1.63 \\
Credit Growth, 2007-2004 & $0.68^{*}$ \\
C & 0.40 \\
& $-0.07^{\star}$ \\
N & 0.04 \\
Adjusted R-squared & $27.59^{\star * *}$ \\
\hline
\end{tabular}

Note: the dependent variable is the percent change in output from trough to latest. Recession is measured as the percent change in output from peak to trough (dates vary for each country). Log GDP/capita, 2007 is the natural logarithm of per capital GDP (current USD) in 2007. Current account balance is expressed as a share of GDP before the crisis. Trade openness is measured as (exports+imports)/GDP. OIL dummy takes the value 1 for oil exporters and zero otherwise. Hard peg dummy takes the value of 1 for de-factor hard-peg exchange rate regimes as classified by the IMF, 2006. Intermediate peg categorization follows the same classification. Trading partner growth is the percent change in real GDP of trading partners during the recovery (WEO, GEE assumption series). Credit growth is defined as the change in the ratio of private credit to GDP betwen 2004 and 2007. 
7. Estonia and Lithuania rank among the fastest growing economies in the region. In the case of Lithuania, cumulative growth of 8.5 percent from the trough has been very close to the predictions of the model. In Estonia growth has exceeded the predictions of the model, notably on account of an impressive export performance. By contrast, growth in Latvia has fallen short of the model prediction, possibly because the model attributes a higher weight to the (positive) catch-up effect relative

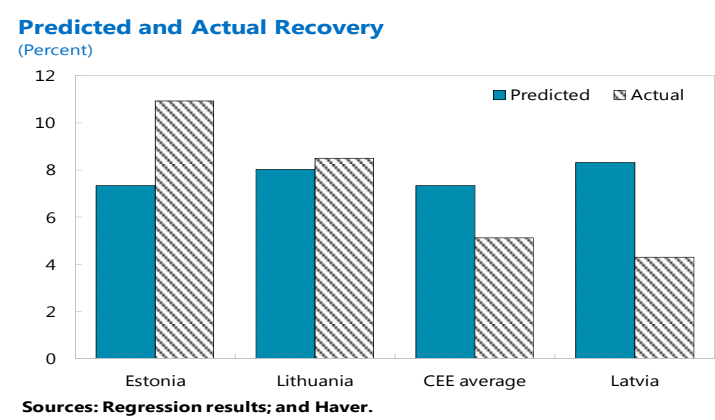
to the (negative) pre-crisis imbalances effect.

Variables Affecting the Strength of the Recovery
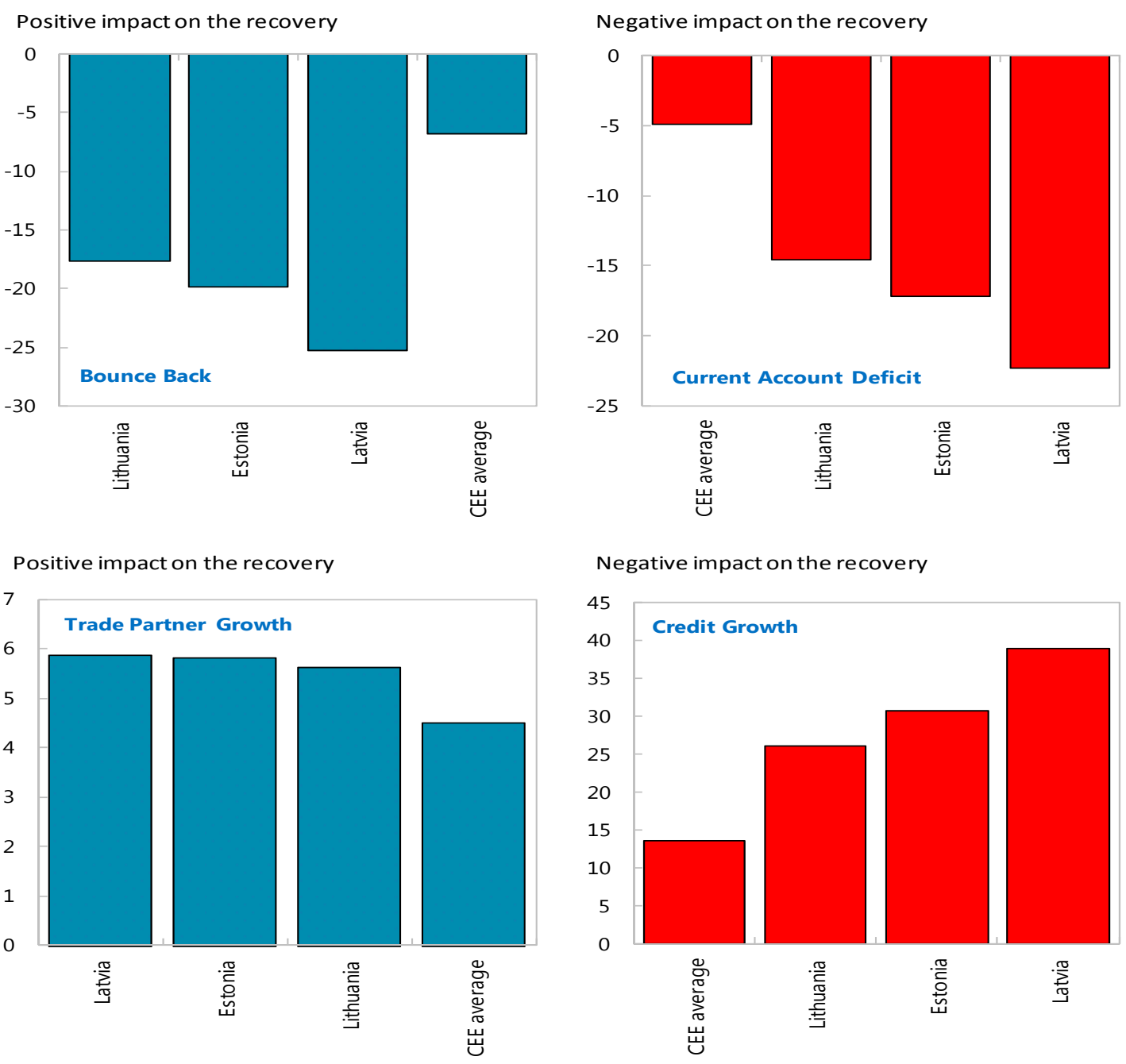

Sources: WEO, HAVER, IMF staff calculations. 


\section{The Recovery}

8. Strong relative price adjustment and favorable external demand following the crisis have helped Lithuania recover at a fast pace. In this section we look at the adjustment process and the composition of growth during the recovery.

9. The currency board arrangements in the Baltic countries required an internal adjustment of prices to correct imbalances. Unlike a floating exchange rate regime where relative prices can adjust by allowing the nominal exchange rate to depreciate, a hard peg necessitates a downward correction of domestic prices, notably in sectors where pre-crisis imbalances were most acute. This is indeed what happened in the Baltic countries. The adjustment of overall wages was fastest and sharpest in Lithuania, with the decline in the construction sector being the largest. All in all, sharp nominal wage declines in these countries underlined the flexibility of wage adjustment.
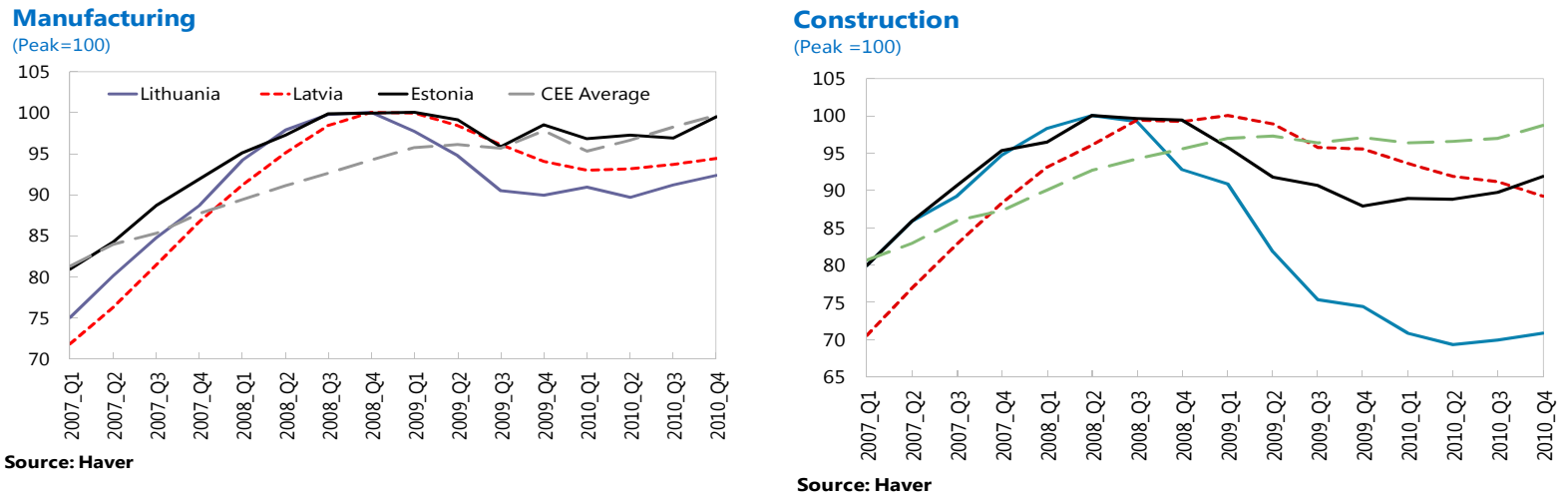

10. Internal adjustment has led to an improvement in competitiveness, which has been reflected in export performance. The manufacturing ULC-REER has depreciated significantly in the Baltic countries. In Lithuania, the manufacturing-ULC REER is now back to its 2003 level. Gains in competitiveness have been reflected in a remarkable export performance in Estonia and Lithuania. Both these countries have outperformed the average of CEE countries, which have historically been export-driven economies. The exception among the Baltic countries is Latvia, which has had below-average export growth despite a significant real depreciation.

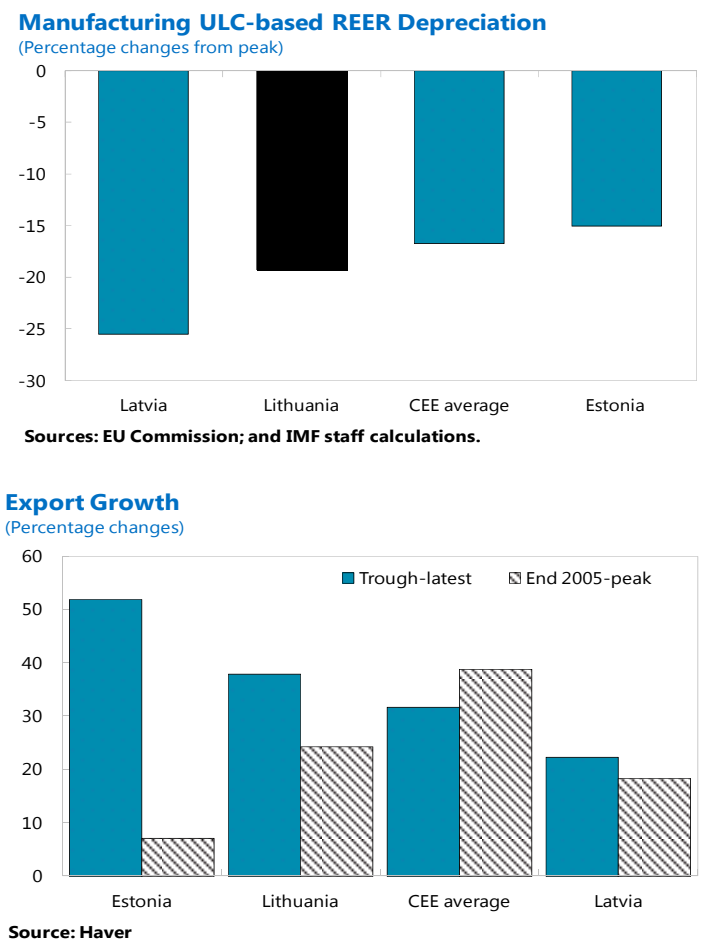




\section{Strong export growth has been} reflected in an increase in the contribution of tradable sectors to output growth. In

Lithuania, tradable sectors have accounted for more than 50 percent of output growth since the trough. The share for Estonia is 66 percent and even higher in Latvia. Now, does this reflect a sustained shift towards a tradable-based economic model, or is it simply the product of temporary factors?

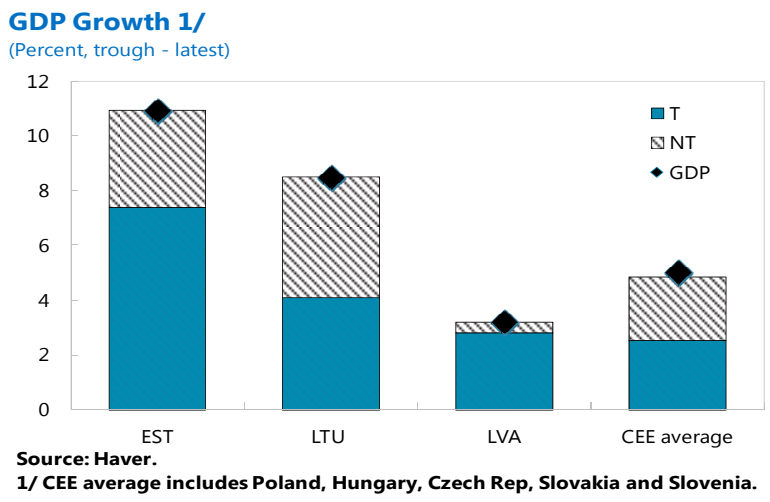

12. There is tentative evidence of labor re-allocation towards tradables. Total employment in the Baltics has increased only marginally during the recovery. In Estonia and especially Latvia, most of the increase in employment has come in manufacturing, while employment in most other sectors has declined. In Lithuania, manufacturing employment continues to contract; however, there have been gains in transportation, which (though classified as a non-tradable sector in this study) has an important tradables component. ${ }^{6}$ In short, signs of labor re-allocation are only tentative so far, but this could be a matter of time given the difficulties in overcoming skill mismatches. In this respect, structural reforms enhancing labor reallocation will be important during this process to avoid the risk of high structural unemployment.

\section{Contribution to Total Employment by Sector}
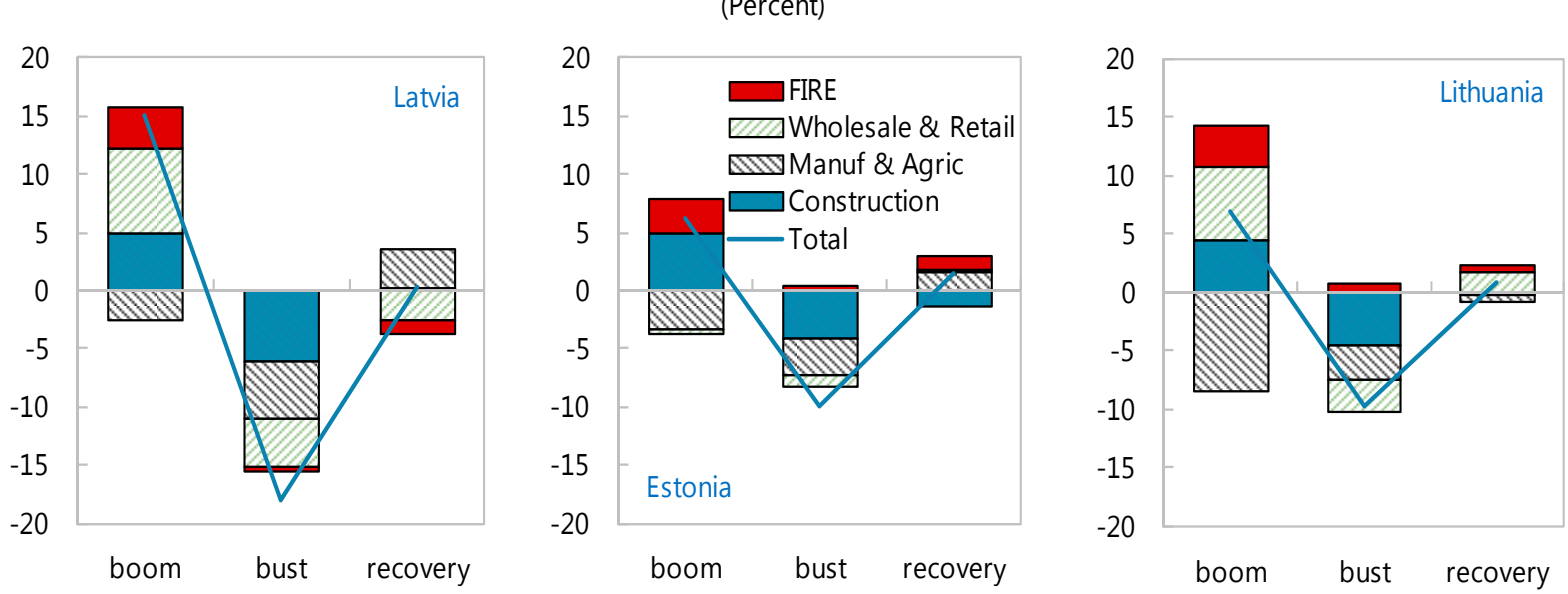

Source: Eurostat; and IMF staff calculations.

13. While total FDI flows have declined considerably compared to 2007, flows to manufacturing have remained roughly unchanged. Total FDI flows into Lithuania declined from 5.2 percent of GDP in 2007 to 1.7 percent in 2010. However, the decline has

\footnotetext{
${ }^{6}$ For employment, tradable sectors are defined as manufacturing and agriculture. However, other sectors may have significant tradable components, depending on the country.
} 
been fully driven by sectors like financial intermediation and real estate. A similar pattern is apparent in the other Baltics, where most of the decline in FDI flows has occurred in non-manufacturing sectors. In fact, in Estonia manufacturing FDI is now higher than before the crisis.
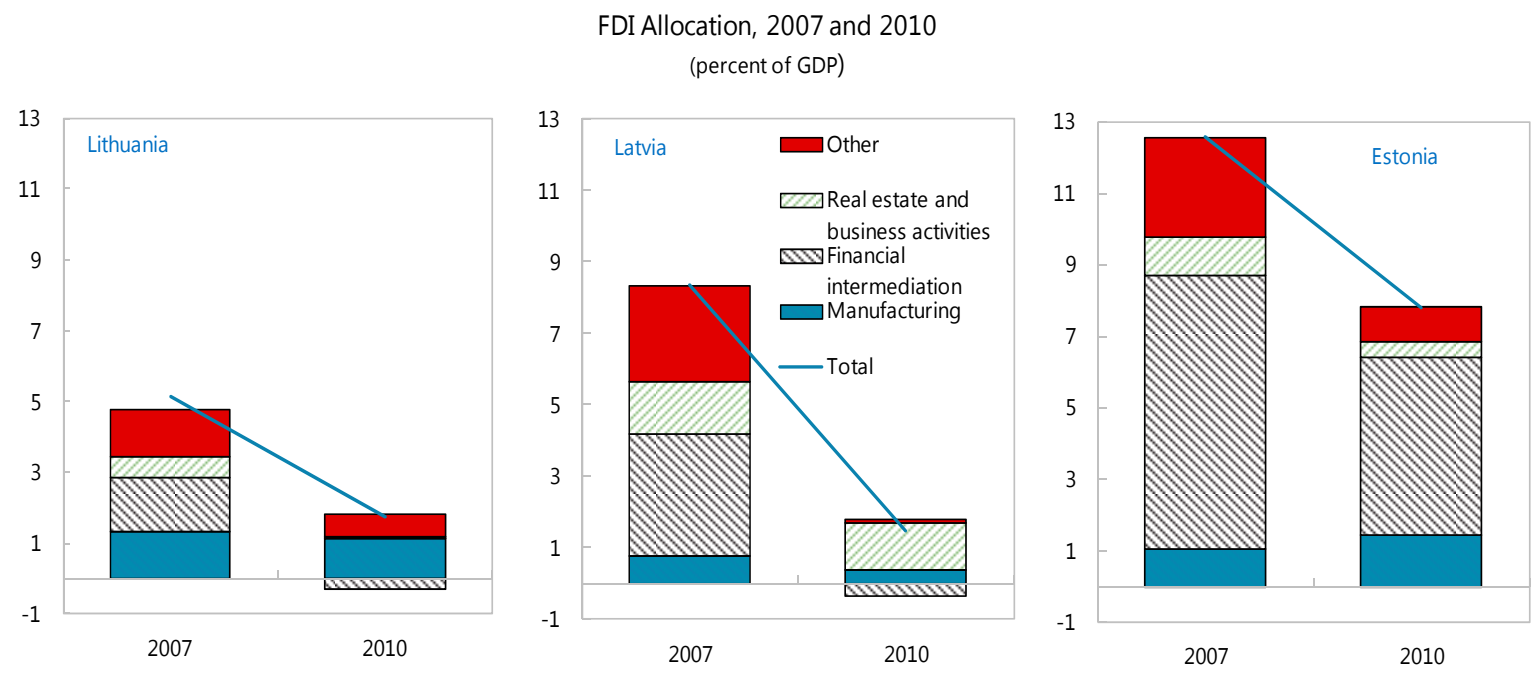

Source: Central Banks and national statistical officies

14. Similarly, the decline in credit has been most apparent in non-tradable sectors. In the absence of direct data on investment/capital stock by sector, we use credit data to proxy for capital re-allocation. Across all three Baltic countries, construction and real estate have experienced the greatest contraction of credit.

Loans to Non-financial Corporations, 2007 and 2010

(percent of GDP, flows)
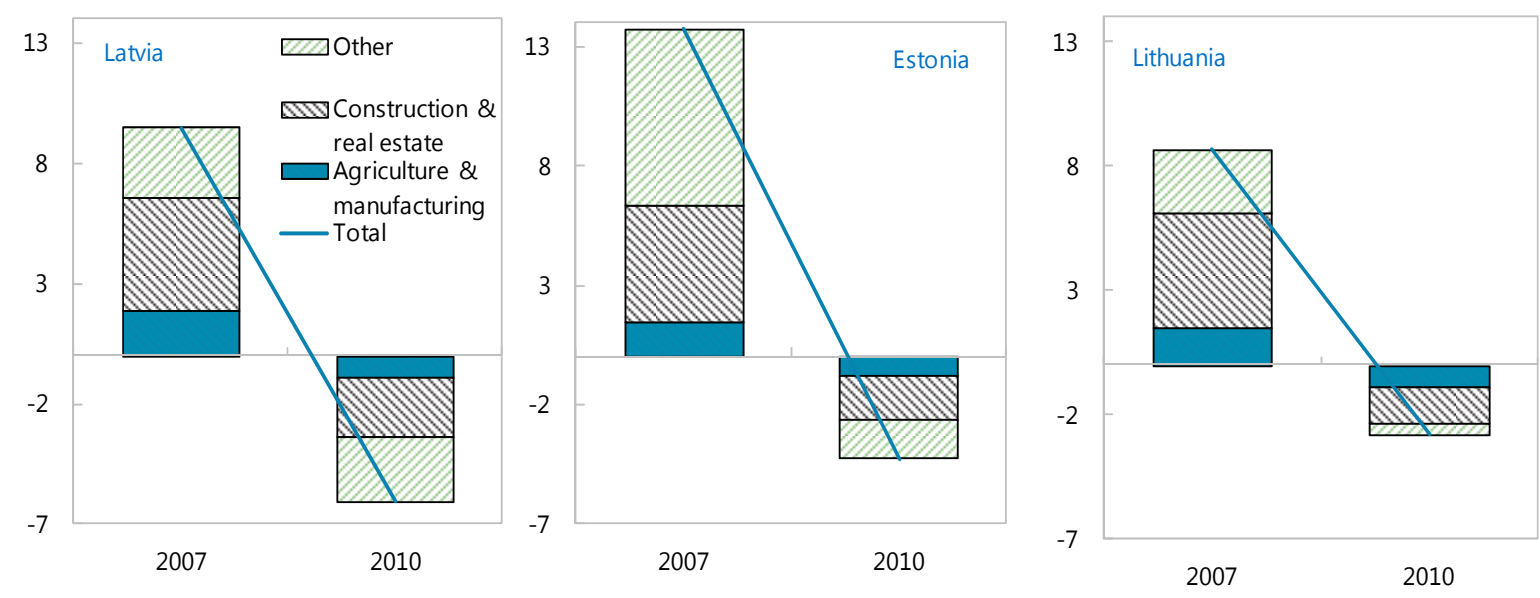

Sources: National Central Banks, Haver, IMF staff calculatons. 


\section{Conclusions}

15. Lithuania has been among the fastest recovering economies in the region thanks to strong exports, but the rebalancing of growth towards tradable sectors is not yet firmly entrenched. Strong export performance has resulted in a large increase in the contribution of tradables to growth. However, the resource re-allocation required to sustain this shift is only just getting under way, perhaps because of the time required to overcome large skill mismatches left by the crisis. Going forward, it will be important to ensure that the large competitiveness gains of recent years are not eroded, as these will form the bedrock of any export-based growth model. 


\section{References}

Didier, T, H.Constantino, and S. Sergio L, 2011, "How Resilient Were Emerging Economies to the Global Crisis?”, World Bank, Policy Research, Working Paper WPS 5637.

Fischer, Stanley, 2007, "Exchange Rate Systems, Surveillance and Advice”, Mundell-Fleming Lecture.

International Monetary Fund, 2010a, Lithuania, Selected Issues Paper, “Does Lithuania Have a Competitiveness Problem?" IMF, Country Report No. 10/202. (Washington: International Monetary Fund).

International Monetary Fund, 2002, World Economic Outlook, April: Recessions and Recoveries, World Economic and Financial Surveys (Washington). Available via the Internet: http://www.imf.org/external/pubs/ft/weo/2002/01/

International Monetary Fund, 2009, World Economic Outlook, April: Crisis and Recovery, World Economic and Financial Surveys (Washington). Available via the Internet: http://www.imf.org/external/pubs/ft/weo/2009/01/

Landesmann, M., 2010, "Which Growth Model for Central and Eastern Europe after the Crisis?” Policy Brief No.4, Vienna: The Vienna Institute for International Economic Studies.

Lane, P.R., and G.M. Milesi-Ferrett, 2010, “The Cross-Country Incidence of the Global Crisis,” IMF Working Paper No. 10/171 (July).

Park and Lee , 2001, "Recovery and Sustainability in East Asia", NBER, Working Paper, No. 8373.

Purfield, Catriona, and Rosenberg, Christoph B., 2010, Adjustment Under a Currency Peg: Estonia, Latvia and Lithuania During the Global Financial Crisis 2008-09 (September). IMF. Working Papers, Vol., pp. 1-34. 


\section{Appendix I. Data Definitions and Sources}

\section{OIL}

The list of oil exporters includes Algeria, Angola, Azerbaijan, Bahrain, Canada, Republic of Congo, Ecuador, Equatorial Guinea, Gabon, Iran, Kazakhstan, Kuwait, Libya, Mexico, Nigeria, Norway, Oman, Qatar, Russia, Saudi Arabia, Sudan, Syria, Trinidad and Tobago, Turkmenistan, United Arab Emirates, Venezuela, and Yemen.

\section{De Facto Exchange Rate Classification ${ }^{1}$}

\section{Category: PEG Countries}

No separate legal tender, Currency

Board and Other fixed pegs

Advanced (29)

Emerging (22)
Argentina, Bulgaria, Denmark, Ecuador, El Salvador, Estonia, Hong Kong, Latvia, Lithuania, Russia,Venezuela.

Austria, Belgium, Canada, Cyprus, Czech Rep, Denmark, Estonia, Finland, France, Germany, Hong Kong, Iceland, Ireland, Italy, Korea, Luxemburg, Malta, Netherlands, New Zealand, Norway, Singapore, Slovakia, Slovenia, Spain, Sweden, Switzerland, Taiwan, UK, U.S.A.

Argentina, Brazil, Bulgaria, Chile, Costa Rica, Dominical Rep, El Salvador, Georgia, Guatemala, Hungary, Latvia, Lithuania, Malaysia, Mexico, Paraguay, Peru, Philippines, Romania, Russia, Serbia, South Africa, Thailand, Turkey, Ukraine, Venezuela

\footnotetext{
${ }^{1}$ De Facto Classification of Exchange Rate Regimes and Monetary Policy Framework, IMF 2008.
} 


\section{How Fast Can The Baltics Grow In The Medium Term? ${ }^{1}$}

Drawing from the empirical growth literature, this paper finds that potential output growth has fallen in the Baltics as a result of the crisis, imperiling the process of income convergence towards wealthier European counterparts. A key reason is the very sharp decline in investment ratios that has occurred since 2007. Put simply, these countries are not increasing their productive capital enough, and labor productivity growth is likely to stall as a result. Sustaining the convergence process thus calls for policies that are conducive to investment. It also calls for labor market policies to achieve higher employment participation in the face of a declining labor force and skill mismatches.

\section{A. Introduction}

\section{For the Baltics, the crisis has}

\section{stopped the process of income} convergence dead in its tracks. Prior to the crisis, rapid income growth was helping these countries catch up to their richer western European counterparts. At the time, this process was seen as strong evidence of neoclassical convergence, facilitated within Europe by the free movement of capital and, to a lesser degree, of labor as well. But the crisis has hit the Baltics harder than any other region in the world, reversing part of the relative

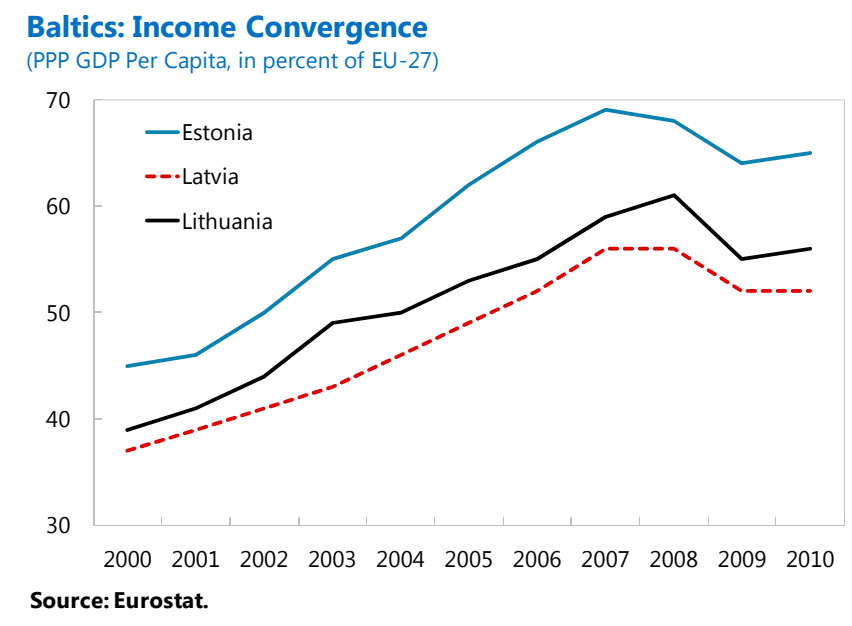
income gains achieved in years prior. Sure enough, some of these gains were the result of unsustainable growth models built on cheap credit and associated booms in non-tradable sectors. But this, if anything, only adds urgency to the question: can these countries resume convergence, or will they be locked in for a long time at substantially lower relative standards of living?

\section{In this context, medium-term growth prospects are key, and are the focus of this}

paper. Current estimates of medium-term growth for the Baltics typically draw on the staff's country-specific knowledge. For instance, potential output in the medium-term may be derived from a production function that reflects the staff's assumptions about the future rate of factor accumulation and of technical progress in the country. This paper takes a different approach, deriving estimates of medium-term growth in the region from stylized regressions drawn from the empirical growth literature. While such regressions have well-known limitations which will be discussed below, their systematic use of cross-country variation can provide a useful complement to country-specific methods. The paper is organized as follows;

\footnotetext{
${ }^{1}$ Prepared by Jacques Miniane.
} 
Section II will discuss the model predictions and implications for convergence; Section III will draw some tentative policy implications; and, Section IV will conclude.

\section{B. Medium-Term Growth Prospects}

3. Standard growth regressions can be used to "predict" future growth. Following seminal work by Barro (1991), a large literature has tried to explain variations in growth outcomes across countries. Econometric specifications vary within this literature, but it is typically the case that growth at time $t$ is explained by initial conditions, ie. variables pre-dating $t$. In such a set up, just as one can use, say, 1999 values to explain growth over 2000-05, one can use known 2010 values to "predict" post 2010 growth, which is our object of interest.

\section{This paper relies on two different specifications based on well-accepted} regressors. Rather than stipulating and estimating new equations, we rely on specifications that have proven to have good explanatory and predictive power specifically for Eastern European growth. ${ }^{2}$ Having two rather than one specification allows for more robust inference; also, since the models rely on somewhat different sets of regressors, they can provide complementary insights. The models' regressors are standard in the literature, and include initial income-knowing that convergence is an important driver of long-run growth-the investment/GDP ratio or the relative price of investment goods, measures of education levels, measures of institutional quality, measures of the quality of macroeconomic policies (such as inflation), partner country growth, the country's degree of openness to international trade, and, given that these are post-transition countries, the degree to which they have completed transition.

\section{Using empirical regressions to estimate medium-term growth prospects has pros} and cons in the current context. Because most of the explanatory variables are past (typically 2009 or 2010) values of known variables, predictions do not have to rely on "guessing" uncertain future outcomes. ${ }^{3}$ Also, the models, by construction, can shed useful light on the quantitative importance of each factor in explaining any decline in potential growth in the region, and by extension can give hints on policy priorities to arrest or minimize such a decline. At the same time, parameter uncertainty is also the models' main liability, particularly at a time of tremendous structural change in the Baltic and global economies.

\footnotetext{
${ }^{2}$ See Appendix for details. The specifications are drawn from Schadler et al. (2006) and Vamvakidis (2008), respectively denoted "OP model" and "REO model" in some of the charts. The R-squareds of these two specifications is about 0.6 . Because most regressors are expressed as initial conditions, the R-squared can be thought of as a measure of the models" "forecasting" ability.

${ }^{3}$ One important exception is partner country growth, which in the regressions is measured over 2011-16 and comes from the WEO.
} 
6. Turning to the results, the models predict substantially slower growth going forward, with reassuringly little variation in predictions across models. By and large, the models predict medium-term growth in the $3 \frac{1}{4}-4 \frac{1}{4}$ percent range, some 4 to 5 percentage points lower than during the 2002-07 boom. Of note, differences in predictions across the two models are pretty small for Estonia and Latvia, less so for Lithuania where one of the two models predicts growth closer to $2 \frac{1}{2}$ percent. This particular model puts emphasis on investment as a key driver of growth, and in 2010 Lithuania had the lowest investment ratio in the Baltics

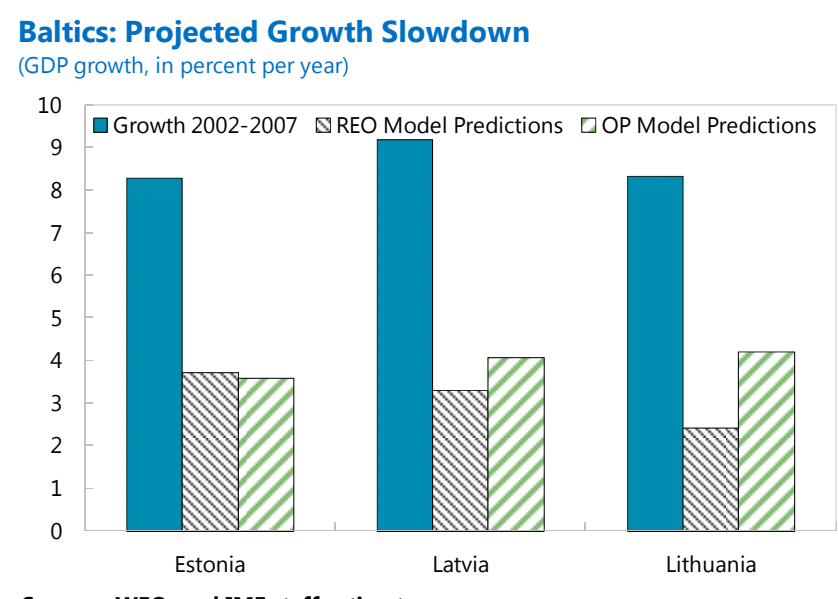
and one of the lowest in Eastern Europe.

7. The slowdown predicted by the models owes in part to the fact that pre-crisis growth was out of line with fundamentals. Had the models been estimated in 2001 with real time data, they would have predicted some $6 \frac{1}{2}$ percent growth during the boom period. The difference between actual growth rates and this prediction, which is about $2-2 \frac{1}{2}$ percentage points per year, can be thought of as the component of pre-crisis growth that exceeded what was arranted by fundamentals.

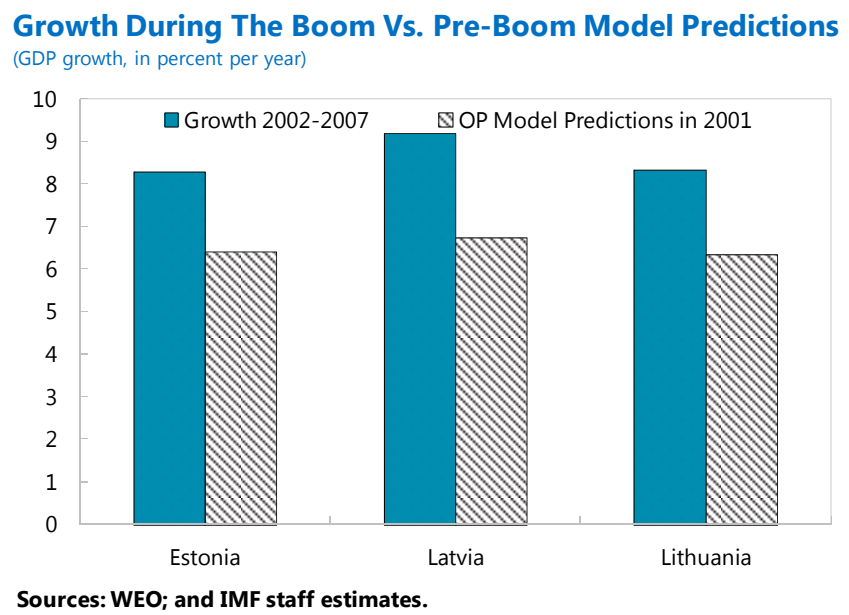

8. However, the reasons for the decline in growth going forward go beyond excessive growth in the past. According to the models, there are three key reasons:

- Despite the crisis, income per capita is higher now than it was before the boom. Conditional convergence-i.e. the idea that ceteris paribus poorer countries tend to grow faster than richer countries and catch up-has been validated over and over in growth studies. All three Baltic countries are richer in per capita terms in 2010 than they were in the early 2000s despite the collapse in output over 2008-09, and hence should be 
expected to grow more slowly going forward. ${ }^{4}$ To measure how large this effect is, we compute what the models would predict for future growth if all regressors were at contemporaneous values but income per capita was at 2002 instead of 2010 values. In all three countries, the increase in income per capita subtracts a non-trivial $3 / 4$ percentage points per year to medium-term growth.

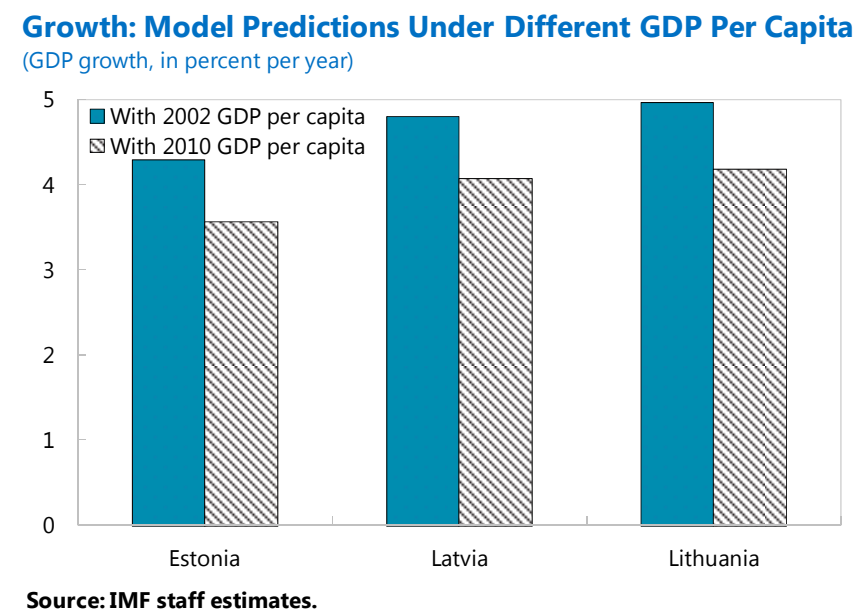

- Partner country growth is expected to be lower going forward. Impressive growth in some emerging markets notwithstanding, there is concern that the world may be entering a new "normal" characterized by lower trend growth. Faced with lower demand for their goods and services, Baltic countries would then be expected to grow more slowly. Comparing the benchmark Growth: Model Predictions Under Different Trading Partner Growth (GDP growth, in percent per year)

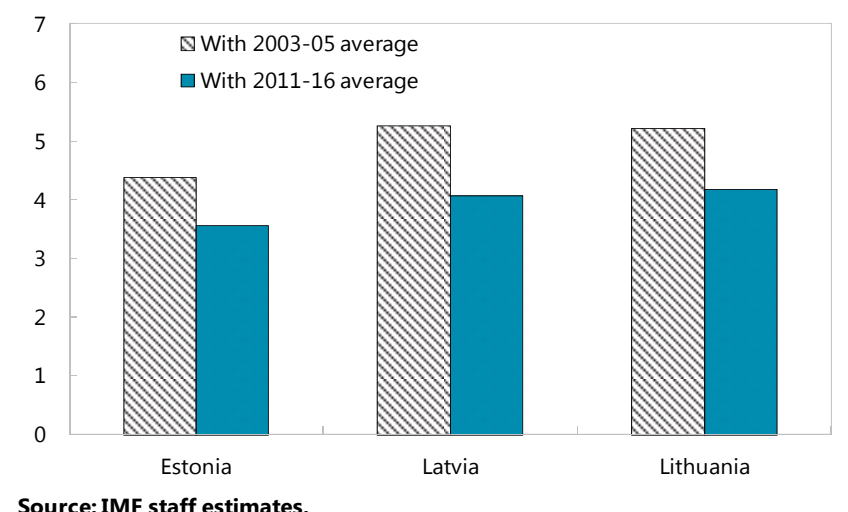
model predictions with predictions using 2003-05 partner country growth as a regressor ${ }^{5}$ shows that the new "normal" accounts for some $3 / 4$ percentage point lower growth in Estonia, $1 \frac{1}{4}$ percentage points in Latvia, and 1 percentage point in Lithuania. At the same time, these could be overestimates. During the boom, partner country growth in the Baltics was exaggerated by the fact that these countries trade substantially with one another, and each was growing well above trend. Also, it is worth pointing out that export elasticities with respect to partner country growth are very volatile in the Baltics, and hence should be treated with caution. For instance, in 2010 and the first half of 2011 Estonian and Lithuanian exports performed well above what standard elasticities would predict.

\footnotetext{
${ }^{4}$ As we saw before, they are not just richer in absolute terms but also relative to EU-27 standards, despite the setback from the crisis.

${ }^{5}$ We use 2003-05 instead of 2003-07 to take out the most "bubbly" pre-crisis years from the calculation.
} 
- Investment ratios in the region have fallen quite dramatically. The level of investment in a country has been repeatedly found to be strongly correlated with growth. In the Baltics, investment ratios were artificially boosted during the boom, but these gains were not just partially but actually more than fully wiped out by the crisis, so that ratios today are well below what they were after the Russian crisis of 1998. And the

Baltics: Fixed Investment/GDP Ratio (Percent)

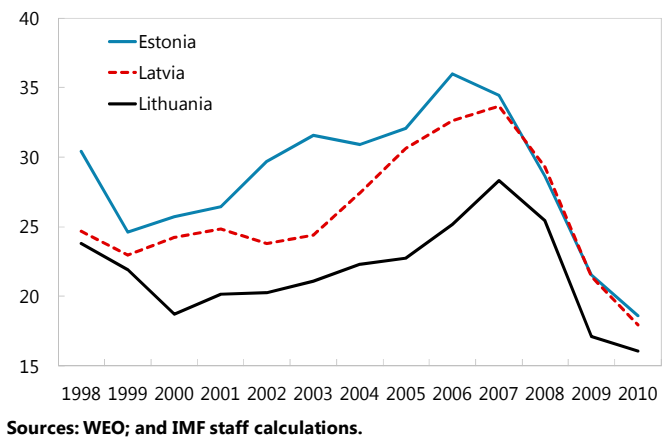
decline has not been limited to construction investment: non-construction investment is now about half the levels seen over much of the last 15 years. In turn, lower investment will lead to sluggish labor productivity which, from a growth accounting

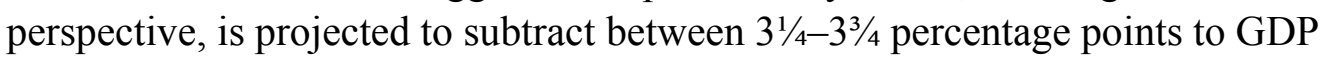
growth per year relative to the pre-crisis boom. Alternatively, if these countries enjoyed today their 1998 levels of investment, then, ceteris paribus, yearly predicted growth would be 1 percentage point higher in Latvia and Lithuania, and $13 / 4$ percentage points in Estonia.

Baltics: Labor Productivity and the Growth Slowdown 1/

(Contribution from labor productivity to GDP slowdown, in percentage points per year)

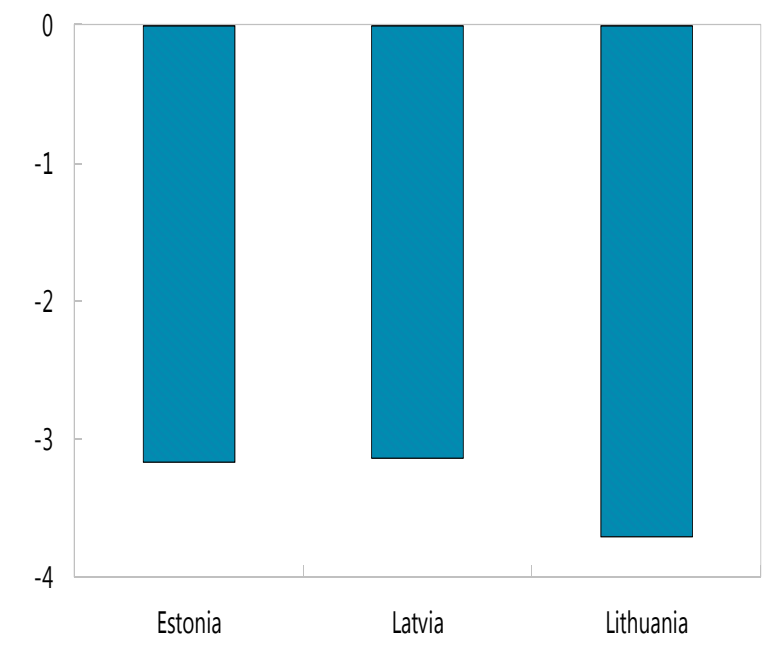

Source: IMF staff estimates.

1/ GDP slowdown defined as model predicted growth minus 2002-07 growth.

\section{Growth: Model Predictions Under Different Investment (GDP growth, in percent per year)}

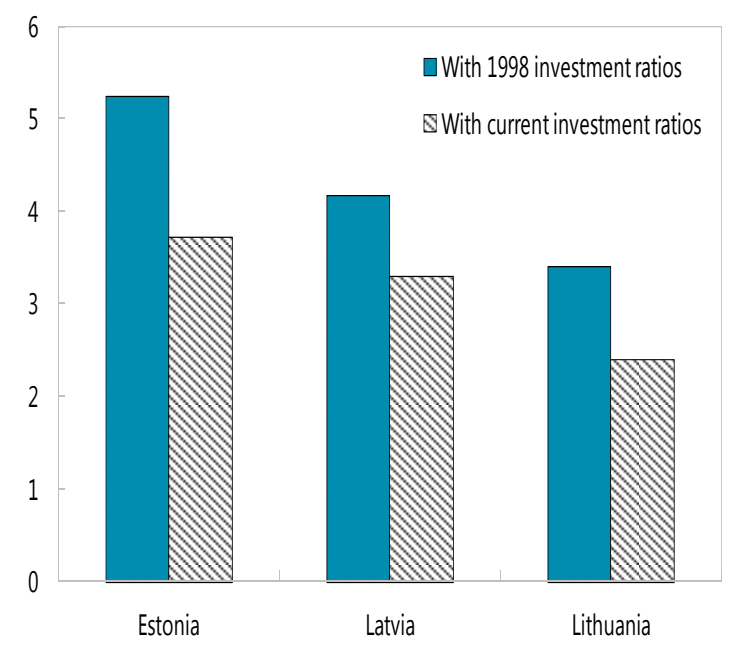

Source: IMF staff estimates.

- Summarizing: These four effects-unsustainable pre-crisis growth, higher initial income per capita, lower projected trading partner growth, and lower investment post-crisis-fully account for the projected decline in growth in the medium-term. 
Growth: Decomposing The Decline

(Percentage points )

\begin{tabular}{lccc} 
& Estonia & Latvia & Lithuania \\
\cline { 2 - 4 } Projected decline in growth 1/ & 4.6 & 5.5 & 5.0 \\
of which: unsustainable component of boom & 1.9 & 2.5 & 2.0 \\
of which: lower partner country growth & 0.8 & 1.2 & 1.0 \\
of which: higher initial income per capita & 0.7 & 0.7 & 0.8 \\
of which: lower investment ratios post-crisis & 1.5 & 0.9 & 1.0 \\
Difference 2/ & -0.3 & 0.2 & 0.2 \\
\hline
\end{tabular}

Sources: IMF staff estimates

1/ Difference in growth between 2002-07 average and medium-term model estimates.

2 /f negative, the factors "overexplain the decline."

\section{Slower projected growth will have profound implications for income convergence. First, the rate of} convergence towards the EU-27 average income level (itself dominated by the largest, wealthiest countries) will slow considerably in all three countries compared with the rates of the last decade. While this is a normal phenomenon as countries catch up, in the case of the Baltics convergence could slow sharply even as incomes remain

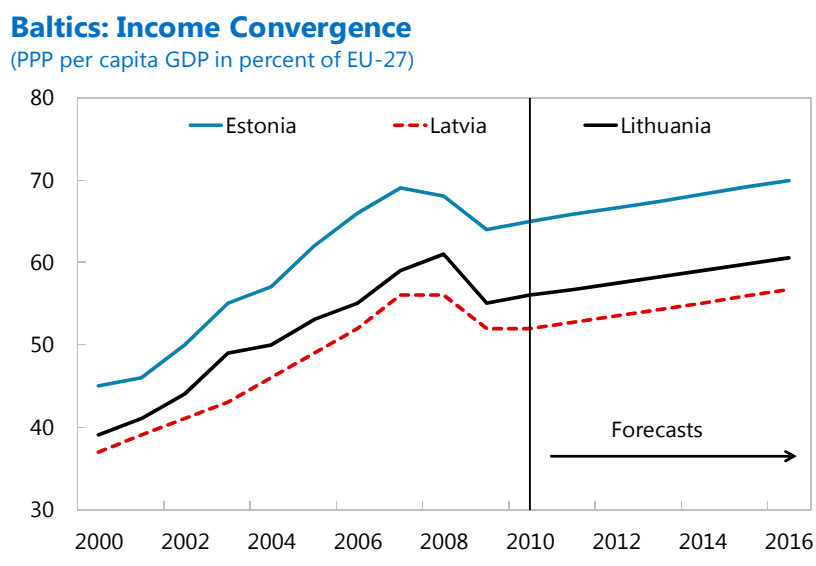

Sources: Eurostat; and IMF staff calculates. between one third (Estonia) and one half (Latvia) below their richer counterparts in Europe. Moreover, the slowdown in convergence speed combined with level losses during the crisis means that, for the Baltics, incomes relative to the EU-27 might not be back to 2007-08 levels before 2015-16; put starkly, the process of income convergence is likely to lose an entire decade.

\section{Finally, it is worth noting that the model predictions of medium-term growth are in line with WEO forecasts. In} Estonia, the two models are very close to each other and almost identical to the WEO medium-term forecasts. ${ }^{6}$ In Latvia, one model predicts the same growth as staff, while the other predicts $3 / 4$ percentage point higher growth. In Lithuania, one model predicts growth about $1 / 2$ percentage point higher than the WEO, the other about

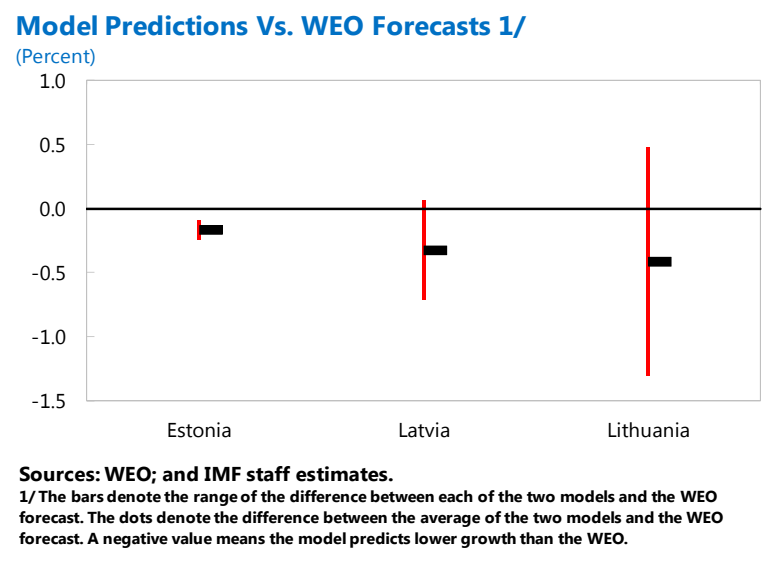

${ }^{6}$ These are September 2011 forecasts. We take the average of the 2014-16 growth forecasts to remove possible cyclical components in 2011-13 numbers. 
$1 \frac{1}{4}$ percentage point lower. In all three cases then, the difference between the WEO forecast and the average of the two models is less than $1 / 2$ percentage point.

\section{Some Policy Implications}

\section{Creating an environment that is conducive to investment will be key to} sustaining growth going forward. While the models pinpoint several reasons why growth might be lower in the future, depressed investment is one which policies can influence. Action on several fronts could help in this regard:

- $\quad$ Maintaining macroeconomic predictability: Baltic countries have gone to great lengths to safeguard their currency boards, minimize fiscal deficits, and preserve financial stability in the face of extremely adverse conditions. Progress over the last two years is there for all to see, capped by Estonia's entry into the euro. While some challenges remain, notably in Latvia and Lithuania where fiscal deficits remain high and banking systems somewhat weak, Baltic countries have earned credibility as they tackle these outstanding weaknesses.

- $\quad$ Boosting investment via greater absorption of EU funds. These funds will play a key role in the face of limited fiscal space, as the Baltics continue to consolidate public finances. There have been clear efforts to accelerate absorption of EU funds, and these efforts have started to pay off. For instance, in Lithuania, EU funds in the budget accounted for 2.7 percent of GDP in 2010 versus only 0.8 percent in 2005 . Nonetheless, administrative bottlenecks including limited resources to conceive, cost, and operationalize infrastructure projects continue to thwart these efforts, with actual absorption typically falling short of budget plans. Finally, it is worth noting that EU funds can also play a catalyst role for investment outside the budget, as witnessed by programs financed with these funds which provide credit guarantees to small and medium-sized businesses.

- Deepening structural reform. Latvia and Lithuania have recently engaged in reform of state-owned enterprises. With these accounting for substantial chunks of their respective economies, enhancing their efficiency could be key to investment in particular and to growth more generally. Beyond SOEs, all three countries are working towards making the business environment friendlier, simplifying overtly complex regulations, minimizing intrusive inspections, or enhancing information resources for small businesses.

- $\quad$ Attracting high quality FDI. In Latvia and Lithuania, the FDI-to-GDP ratio is relatively modest by the standards of central and eastern European countries. Moreover, much of the inward FDI attracted during the boom fed into non-tradable sectors. There is tentative evidence that FDI is rebalancing towards tradables, a welcome development. 


\section{Nonetheless, even with good policies it would be prudent to have modest}

expectations regarding the investment recovery. The experience in Asia after the 1997-98 crisis is instructive in this regard. Like the Baltics, many Asian countries had seen their investment ratios rise rapidly and then collapse when the crisis hit. Yet, as Figure 1 shows, ten years after the crisis these ratios still remain at post-crisis lows in many of the affected countries. Consistent with the results in the previous section, lower investment ratios in Asia came hand in hand with a decline in trend labor productivity and GDP growth post-crisis. As IMF (2006) shows, the reasons for the slump in investment in Asia are not entirely clear: the health of both financial and non-financial corporates improved markedly over the period; macroeconomic vulnerabilities were reduced; and evidence of diversion of investment towards China is not conclusive. Whatever the reason, if the experience in Asia is anything to go by the Baltics could suffer depressed investment for years to come.

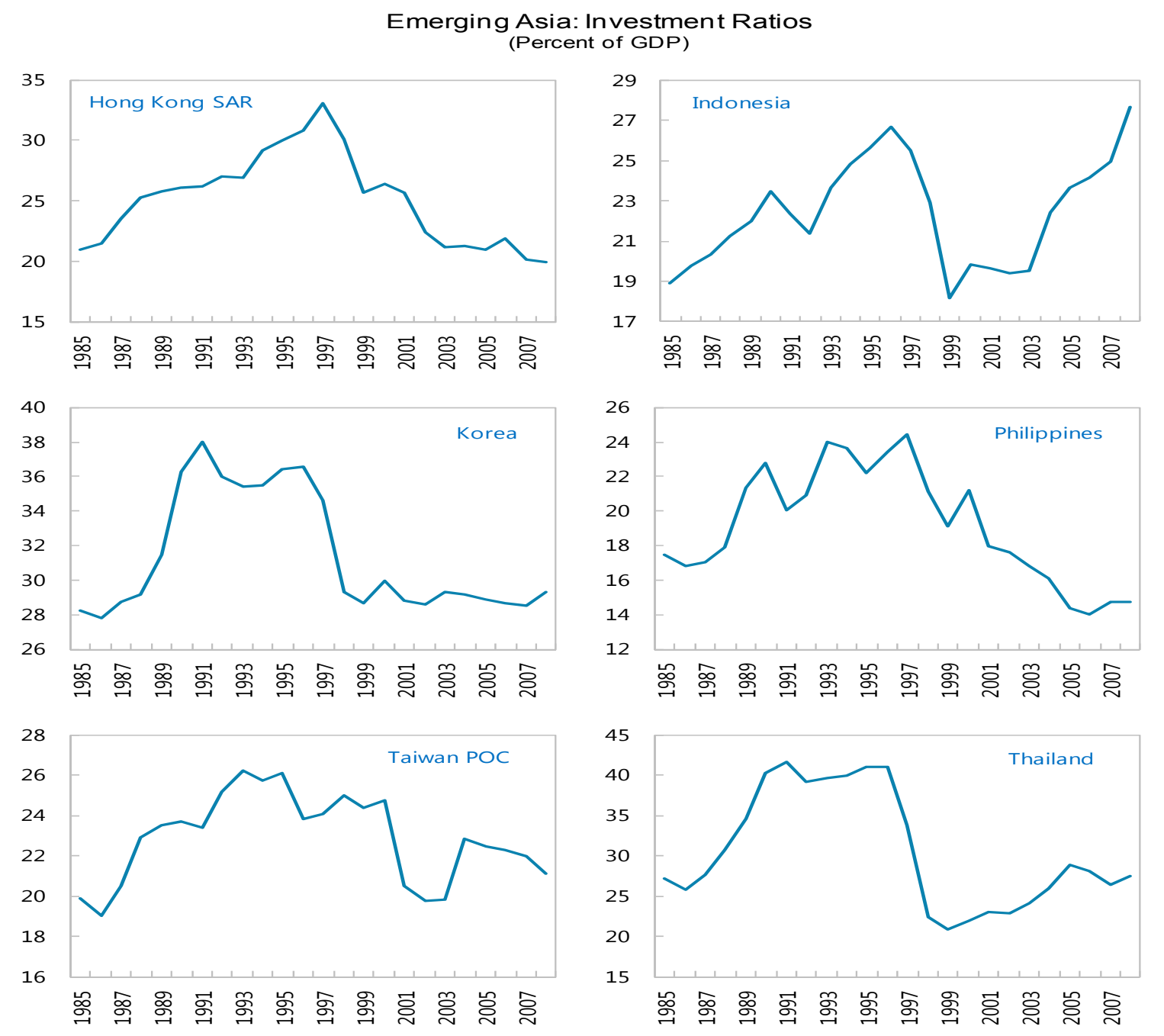

Source: WEO; and IMF staff estimates. 


\section{Boosting employment}

participation policies should also be a

priority. Labor markets in the Baltics gave proof of their remarkable flexibility during the crisis, and the resulting declines in labor costs are a key reason behind the current export boom, notably in Estonia and Lithuania. Nonetheless, labor markets and related policies will continue to be tested for years to come. Given likely declines in labor productivity and a shrinking labor force in these countries, sustaining even modest

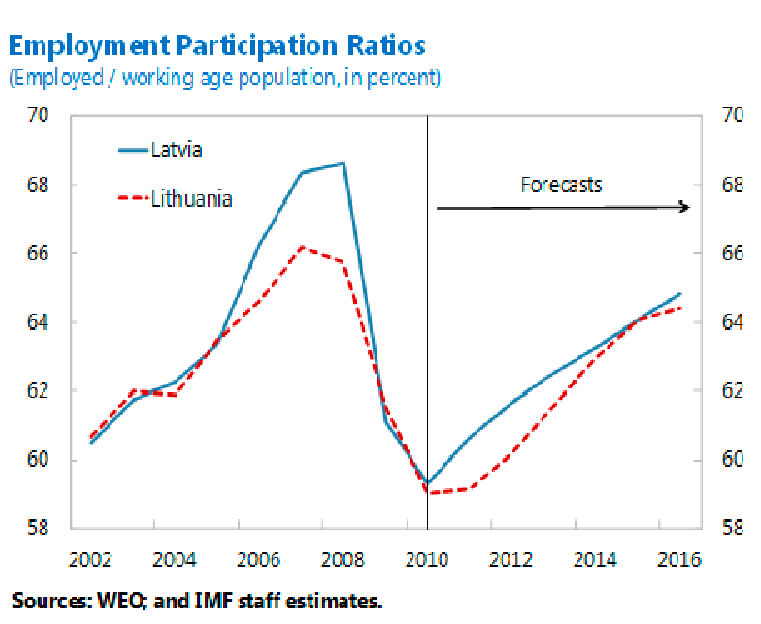

3-4 percent growth will require substantial increases in employment participation ratios, which are projected to rise from about 60 percent now to 65 percent in five years. For this to happen will call for a wide-ranging policy effort, including making greater use of EU structural funds to support job schemes, expand training programs, and improve matching through enhanced labor bureaus. At a more structural level, reforming education systems-such as the recent overhaul of universities in Lithuania-would help better align future labor supply to the needs of the marketplace.

14. A healthy banking sector will be key to support medium-term prospects. While financial variables are not directly incorporated into the models used here, international evidence shows that creditless recoveries tend to be weaker than those supported by healthy bank intermediation (see Abiad et al. 2011). While aggregate credit demand in the Baltics may be constrained for years to come by the need to repair household and corporate balance sheets, it will be important to ensure that healthy firms can access credit when needed. In this respect, the strong provisioning against NPLs that has taken place in most banks, together with proper recapitalizations when these were called for, should help minimize constraints on the supply of credit.

\section{Conclusions}

15. The Baltic countries face modest less bright medium-term growth prospects than a few years ago. True, some of this slowdown reflects a welcome move away from the unsustainable growth model that reigned before the crisis. Still, these countries face major challenges to boost investment and employment in the context of possible continued deleveraging, skill mismatches, and large uncertainty surrounding the global economy. Their flexible economies, and the commitment to strengthen macro and structural policies that they demonstrated in the recent past, will be key assets in meeting these challenges. 


\section{References}

Abiad et al , 2011, Creditless Recoveries. IMF Working Paper 1158.

Barro, 1991, "Economic Growth in a Cross-Section of Countries" Quarterly Journal of Economics, Vol. 106 (2) pp. 407-443.

International Monetary Fund, 2006, “Asia’s Investment Decline”, APD Regional Economic Outlook, Chapter V, (May). Available on the Intranet.

http://www.imf.org/external/pubs/ft/reo/2006/eng/01/areo0506.pdf

Schadler et al, 2006, "Growth in the Central and Eastern European Countries of the European Union” IMF Occasional Paper 252. (Washington: International Monetary Fund).

Vamvakidis, 2008, "Potential Growth Estimates in Emerging Europe Based on a Growth Model", Box 8, EUR Regional Economic Outlook, (April). Available on the Intranet. http://www.imf.org/external/pubs/ft/reo/2008/eur/eng/ereo0408.pdf 


\section{Appendix I. The Models}

The first econometric specification, denoted "OP Model" in the paper and charts, comes from Schadler et al. (2006) and is:

Real per capita GDP growth $=20.68-2.27 *(\log$ of per capita GDP $)-1.27 *$ (population growth $)+0.61 *($ partner country growth $)-0.75 *$ (relative price of investment goods $)+$ $0.2 *($ schooling $)+0.01 *($ openness ratio $)-0.02 *($ government taxation ratio $)+$ $0.03 *$ (institutional quality)

where:

- Per capita GDP is from the Penn World Tables and is measured as of 2009 (or 2010 using 2009 values and 2010 growth rates of PPP per capita GDP from the WEO).

- Population growth is from the World Bank Development Indicators and is measured as of 2009 (latest data point).

- Partner country growth is from the WEO (April 2011, as all other WEO data) and is measured as the 2011-16 average.

- Relative price of investment goods is the ratio of the investment deflator to GDP deflator from the Penn World Tables, and is measured as of 2009 (latest data point).

- Schooling is the average years of secondary and higher education years in the population, from the Barro-Lee database, using the latest available data point for each country.

- Openness is the sum of exports and imports divided by GDP from the Penn World Tables, and is measured as of 2009 (latest data point).

- Government taxation ratio is tax revenue over GDP from the WEO, and is measured as of 2010.

- Institutional quality is the composite risk rating from the International Country Risk Guide, and is measured as of 2010.

The second econometric specification, denoted "REO Model" in the paper and charts, comes from Vamvakidis (2008) and is:

Real per capita GDP growth $=11.00-1.38 *(\log$ per capita GDP $)-7.05 *($ age dependency rate $)+0.13 *($ investment ratio $)+0.02 *($ university enrollment ratio $)-0.015 *$ (inflation rate $)+$ $0.07 *($ FDI ratio $)+0.59 *($ economic freedom $)+0.86 *($ change in economic freedom $)$

where:

- Per capita GDP is from the WEO and is measured as of 2010.

- Age dependency is from the World Bank Development Indicators and is measured as of 2009.

- The investment ratio is the ratio of gross fixed capital formation to GDP from the WEO, and is measured as of 2010.

- The university enrollment ratio is from the World Bank Development Indicators and is measured as of 2008 (latest available data point). 
- The inflation rate is from the WEO and is measured as of 2010.

- The FDI ratio is the ratio of inward FDI to GDP from the WEO, and is measured as of 2010.

- Economic freedom is the index (chain linked summary) from the Economic Freedom Network and is measured as of 2008 (latest available data point). For the change in economic freedom, we assume the index will improve by 5 percent (total) over the next five years in each of the three countries. This assumption is not material to the results.

Note that, unless indicated, all predictions of per-capita GDP growth from the models are expressed in the paper and charts in terms of simple GDP growth, using the relevant forecasts for population growth for the transformation. 


\section{ASSESSING THE VARIABILITY OF TAX ELASTICITIES IN LiTHUANIA ${ }^{1}$}

This paper quantifies the variability of tax elasticities in Lithuania using two alternative methods: rolling regressions and pooled mean group estimator. The analysis is motivated by the systematic variation of tax revenues observed over the economic cycle in the recent past. Both methods confirm that tax elasticities moved with the cycle, which can be attributed to the procyclical tax compliance tendencies and structural composition effects across tax bases. Comparison of VAT revenue gaps across Baltic countries during the recent recovery suggests that tax revenues rebounded fastest in Estonia, followed by Lithuania and Latvia. Overall, the results of the study emphasize the importance of accounting for cyclical variation in tax elasticities when making short-term tax revenue projections.

\section{A. Introduction}

1. Tax elasticities tend to vary systematically over economic cycles. Evidence suggests that tax revenues (including neutral and regressive taxes) tend to fall more sharply than their respective tax bases during recessions, and recover more strongly than bases during booms. Hence, using long-run tax elasticities for short-term revenue projections can lead to overestimation of revenues during contractions and to underestimation of revenues during booms.

\section{The purpose of this paper is to quantify the variability of tax elasticities in} Lithuania and assess where they stand at present. Tax revenues in Lithuania are prone to volatility due to: (i) the structure of the tax system, which relies highly on taxing flows (direct and indirect taxes) rather than stocks (wealth and immovable property), and (ii) macroeconomic flows, such as GDP, private consumption, and the wage bill, which are more volatile than the EU average. This paper analyzes the variability of elasticities for a range of taxes (value added tax - VAT, personal income tax - PIT, corporate income tax CIT, and excise duties - EX) over time, with a particular emphasis on the dynamics during the recent recession. We also analyze the cyclicality of standardized VAT revenue collections (defined as the ratio of VAT revenues to the country-specific statutory rates) in Lithuania relative to other new EU member countries, focusing on the deviations from the long-run equilibrium over the cycle.

\section{We find strong evidence of cyclicality in the elasticity of VAT revenues in}

Lithuania. While the long-run VAT elasticity is close to one, revenue collections deviated from their long-run equilibrium up to 15 percent over the business cycle. Similar to other Baltic countries, deviation of VAT revenues from their long-run equilibrium in Lithuania was positive in the pre-recession boom period (2006-08), but turned negative during the bust. The procyclical behavior of the revenue gap could be attributed to the procyclical tax compliance tendencies and structural composition effects across tax bases. At present, VAT

\footnotetext{
${ }^{1}$ Prepared by Tigran Poghosyan (FAD).
} 
revenues are rebounding to their long-run equilibrium, but remain about 5 percent short of it as of end-2010.

4. The PIT, CIT, and EX elasticities also vary with time, but their dynamics is not fully synchronized. As expected, the PIT and CIT elasticities exceed unity in most part of the sample given their progressivity. The CIT elasticity exhibits the widest range of variation (mainly due to uneven schedule of CIT payments within the year), followed by the EX elasticity. All elasticities have exhibited some increase during the recent recovery, but with different intensity.

5. The rest of the paper is structured as follows. Section B provides a selective literature overview. Section $C$ presents a brief overview of the Lithuanian tax system. Section $\mathrm{D}$ discusses stylized facts. Sections E present estimation results for rolling regression and panel data methods, respectively. The last section concludes.

\section{B. Related Literature on Estimating Tax Elasticities}

6. Most methodological approaches focus on estimating long-run tax elasticities, which are supposed to be constant assuming no changes in the tax system. These approaches are motivated by the observed cyclical adjustment of government revenues and fiscal balance, for which tax elasticities serve as key input. A widely cited reference is Girouard and Andre (1995), which follows the "disaggregated approach" for the cyclical adjustment of government revenues. The authors calibrate elasticities of individual tax categories with respect to their respective bases for 20 OECD countries using tax codes and legislation. These elasticities are then multiplied by the elasticities of tax bases with respect to the output gap to obtain overall tax elasticities that enter the calculations of cyclically adjusted balances. In line with the intuition, the study finds that personal and corporate income taxes are progressive (elasticity is above one), social security contributions are regressive (elasticity is below one), while indirect taxes are neutral (elasticity close to one). ${ }^{2}$ In contrast to Girouard and Andre, Fedelino et al. (2009) and Congressional Budget Office (2009) follow an "aggregated approach", in which elasticities with respect to the output gap are calculated for aggregate government revenues.

7. Despite the long-run constancy assumption, several studies have found that tax elasticities may temporarily deviate from their long-run estimates. One important set of factors contributing to the time variation of elasticities are beyond the cycle effects. While business cycle is the most prominent source of government revenue fluctuations, these revenues can also be affected by shocks related to the boom-and-bust cycles of assets, property prices, and commodity prices, which are not always correlated with the business cycle. For example, Aydin (2010) argues that beyond the cycle effects played a prominent role in explaining highly volatile tax elasticities in South Africa. Another set of factors is

\footnotetext{
${ }^{2}$ In case of the VAT, the elasticity is set to unity without conducting any estimations.
} 
related to changes in the output composition (Bornhorst et al., 2011). For example, an economic expansion driven by private consumption will have a much larger impact on tax collection than an export-driven expansion. Cyclical adjustment does not account for the composition effect, as it only considers the output gap, which could be the same under both scenarios. Finally, tax elasticities can be affected by changes in tax compliance, since firms and households are more likely to evade taxes when they are credit constrained or financially depressed. For example, Sancak et al. (2010) show that the efficiency of VAT collections tends to be lower in "bad" times (when the output gap is negative and informal economy is expanding), and vice versa. In a cross-sectional dimension, it was shown that emerging countries with institutions that are less conducive to tax compliance practices tend to have higher efficiency in VAT collections (Agha and Haughton, 1996, De Melo, 2009, and Aizenman and Jinjarak, 2008).

\section{Brief Overview of the Lithuanian Tax System}

\section{The overall tax burden in Lithuania at about 30 percent of GDP is lower than} the EU average. The proportion of tax revenues received by the central government is slightly below 50 percent, local governments collect about 12 percent of total tax revenues, and the rest is being collected by the social security and extra budgetary funds. Between 2001-2010, indirect taxes comprised 60 percent of total tax revenues and 35 percent of total government revenues. VAT and EX are the main indirect taxes, comprising 38 and 16 percent of total tax revenues, respectively, while PIT and CIT are the main direct taxes, comprising 32 and 10 percent of total tax revenues, respectively.

Trends in Tax Revenue Collections Over the Last Decade
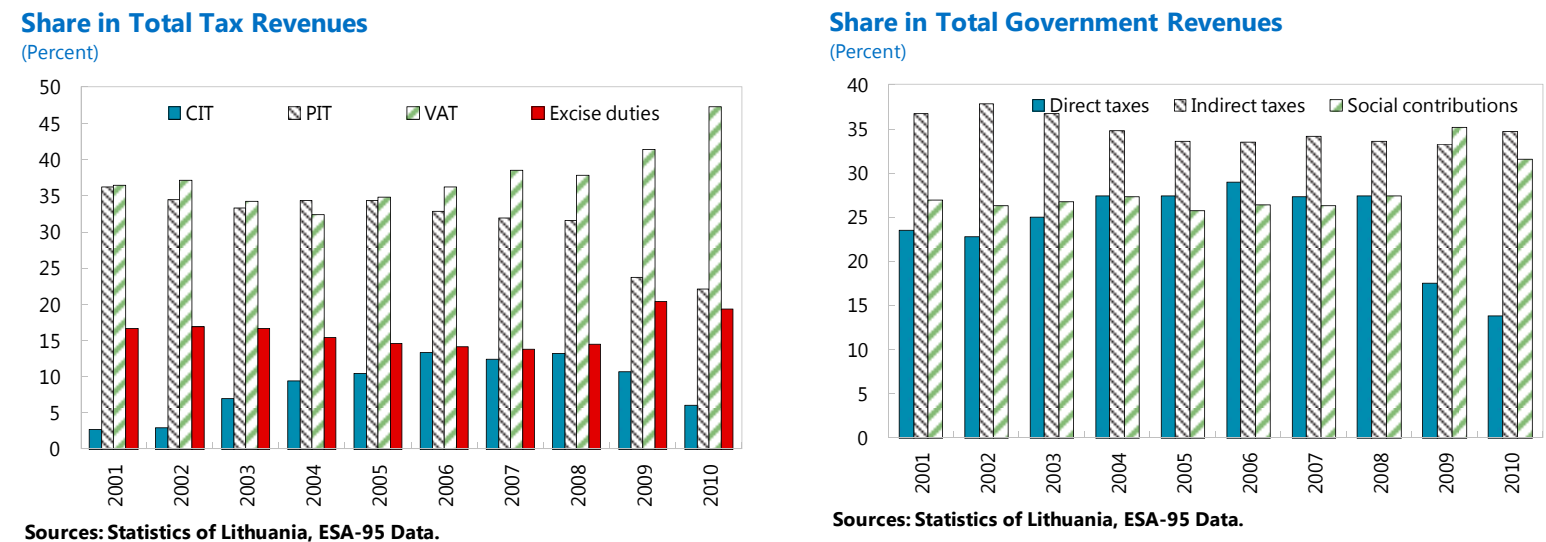

9. The tax structure relies on taxing income and consumption (flows), while taxes on wealth and capital (stocks) are among the lowest in the EU making tax revenues vulnerable to economic fluctuations. The main taxes in Lithuania are PIT, CIT, VAT, and EX. The main characteristics of these taxes broadly correspond to the ones elsewhere in the EU, although it is important to note that CIT and PIT rate changes are easier to implement unilaterally in comparison to VAT and excise duties which face tougher harmonization constraints at the EU level. The tax structure relies on taxing income and consumption 
(flows), while taxes on wealth and capital (stocks) are among the lowest in the EU making tax revenues vulnerable to economic fluctuations.

\section{Social security contributions in Lithuania are comparable to the regional}

average. Social contributions are counted separately from tax revenues and their importance has increased from 2009, when compulsory health insurance contributions have become part of social contributions. The contribution rates were on an upward trend in Lithuania during the last decade, growing from 9.2 percent in 1999 to 11.6 percent in 2009. The 2009 contribution rate of 11.6 percent of GDP corresponds to the average collection in the new EU member countries for the 1999-2009 period.

11. Revenues from property and land taxes are relatively modest. Lithuania collected only 0.37 percent of GDP in property and land taxes in 2010. At present, only commercial property is taxed in Lithuania, with the annual tax being set by the municipalities in the $0.3-1$ percent range. Unimproved land is taxed at 1.5 percent, but numerous exemptions and base reductions apply narrowing the taxable base substantially. There is no net wealth tax.

\section{Stylized Facts}

12. Prima facie evidence hints at time-varying tax elasticities in Lithuania. On the whole, tax revenues contracted more sharply than their respective bases during the recession and tax revenues are rebounding at a faster pace than their bases since the beginning of the recovery in 2010. For example, between 2008-09 VAT collections declined by 25 percent, compared to a 14 percent drop in nominal private consumption during the same period. In contrast, during 2009-10 VAT collections grew by 12 percent, compared to a 3 percent decline in private consumption. The VAT revenue growth outpaced that of private consumption also during the pre-recession boom period. This divergence of tax growth rates and their bases over the cycle is also driven by changes in tax policies, which we account for in our econometric analysis. Nevertheless, the comparison of growth rates provides some indication of a time-varying nature of tax elasticities that we would like to quantify. 
Taxes and Respective Bases
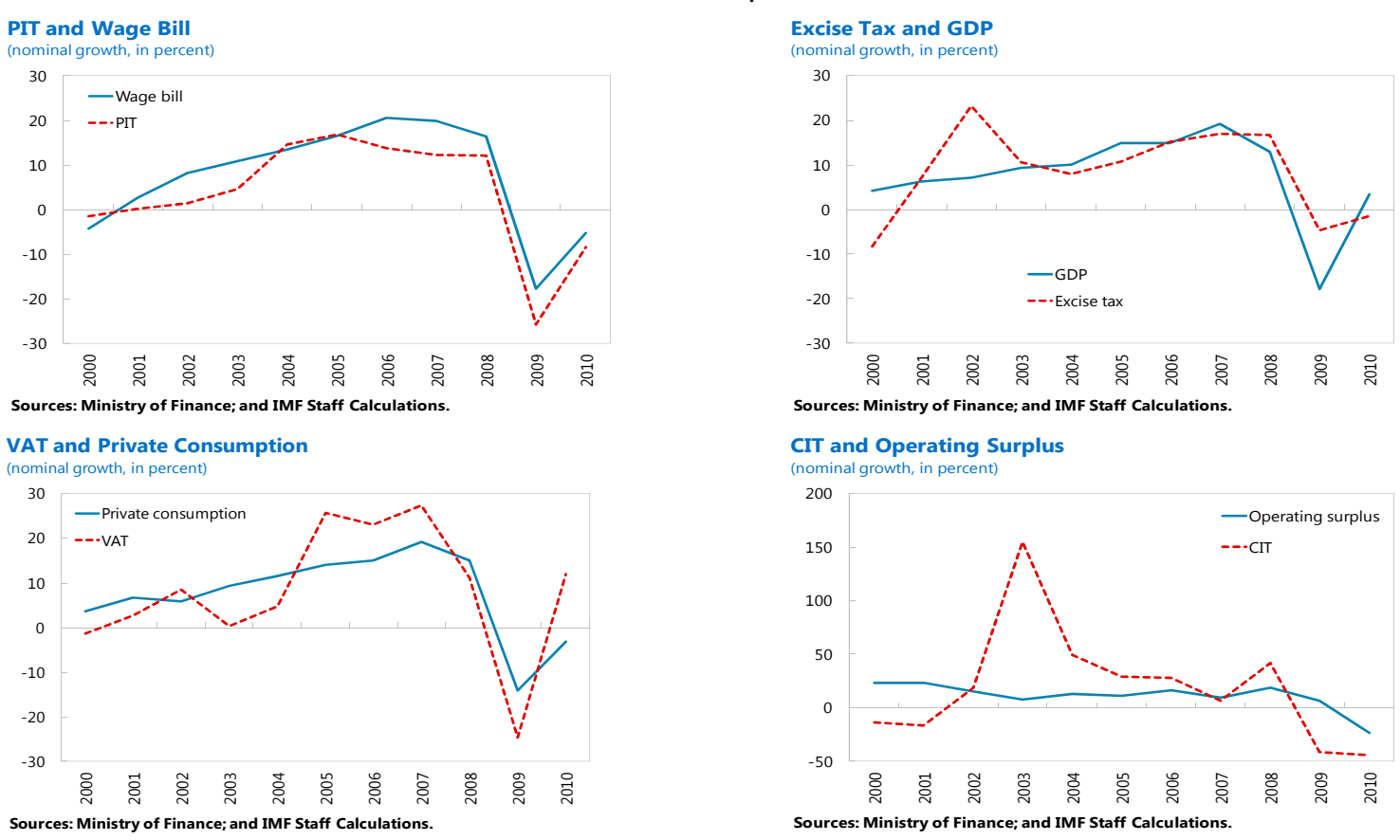

13. For a panel of new EU member countries, analysis of the VAT C-efficiency scores further highlights fluctuations over the cycle as well as across countries. The VAT C-efficiency scores are obtained by dividing the VAT revenue to personal consumption ratio over the VAT statutory rates obtained from the European Commission (a higher score reflects more efficiency, and vice versa). The efficiency scores vary widely across the countries in our sample, with Poland falling in the lower end of the distribution (median score is 55 percent), while Estonia in the upper end (median score is 85 percent, which is very high by international standards). More relevant for our analysis, the efficiency scores also moved widely over time: starting from a median of 57 percent in 1999 they reached a peak of 72 percent in 2007 (pre-recession), and then returned back to 62 percent in 2010 (recovery). The dispersion of scores across countries has also varied across time, recording the lowest range during the pre-recession peak in 2007.

VAT C-Efficiency Across New EU Member Countries
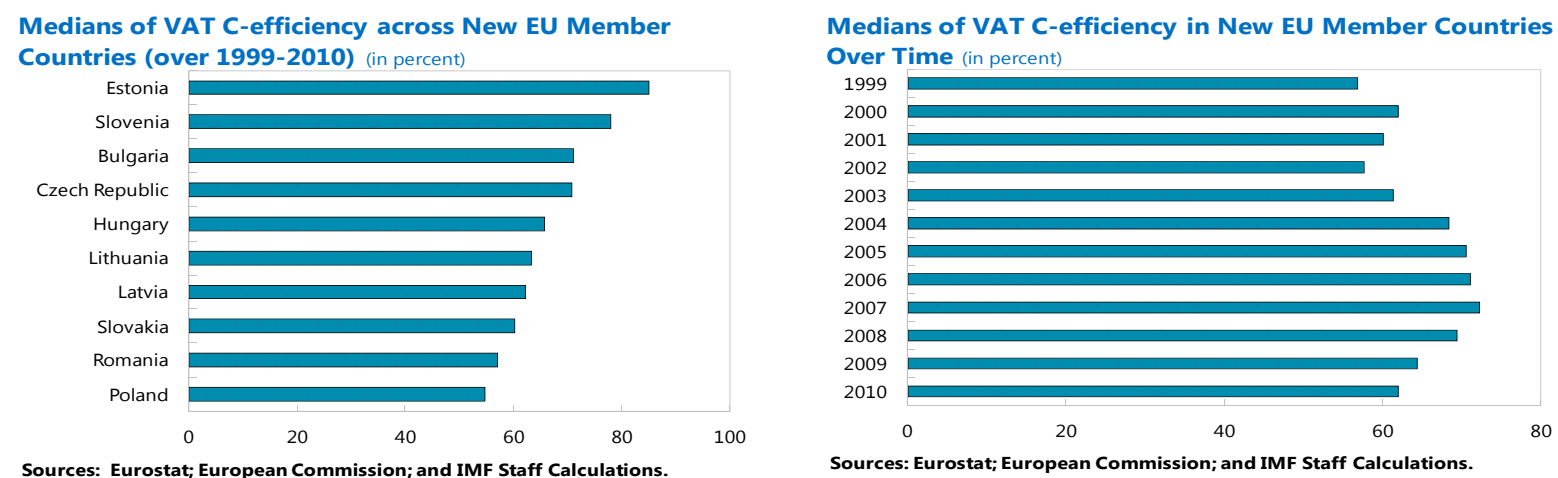

Sources: Eurostat; European Commission; and IMF Staff Calculations. 


\section{E. Estimation Results}

14. We use two methodologies to assess the variability of tax elasticities. First, we apply rolling regression methods to individual taxes in Lihuania. The advantage of this method is that it allows comparing tax elasticities estimated for different subsamples. The drawback is the limited precision of obtained estimates due to the absence of sufficiently long time series. Second, we apply panel data methods to VAT collections in new EU member countries. This methodology overcomes the above mentioned limitation by expanding the number of observations across countries. It also allows comparing revenue collection performance across countries and accounts for substantial part of tax revenues given that new EU member countries largely rely on VAT. However, it cannot be applied to PIT, CIT, and EX, since it is more difficult to measure efficiency for these taxes relative to VAT given considerable differences in tax systems across countries (income distributions, multiple tax brackets, etc.). Unfortunately, the analysis of tax elasticities for social contributions was not possible to conduct given the absence of the pre-2004 quarterly data.

\section{Rolling regressions}

\section{Tax elasticities can be derived from the relationship between cyclical}

fluctuations in tax revenues and their bases. The following relationship has been commonly used as benchmark in the literature (e.g., Bornhorst et al., 2011):

$$
T=T^{*}\left(\frac{B}{B^{*}}\right)^{\varepsilon}
$$

where $T$ is the tax revenue, $T^{*}$ is the structural tax revenue, $B$ is the tax base, $B^{*}$ is the potential tax base, and $\varepsilon$ is the tax elasticity $(\varepsilon>0)$. Depending on the magnitude of $\varepsilon$, the tax system can be progressive $(\varepsilon>1)$, regressive $(\varepsilon<1)$, or neutral $(\varepsilon=1)$. The empirical assessment of tax elasticities is based on equation (1):

$$
\ln \left(\frac{T_{t}}{T_{t}^{*}}\right)=\beta_{0}+\beta_{1} * \ln \left(\frac{B_{t}}{B_{t}^{*}}\right)+\beta_{2} * \operatorname{CONTROLS}_{t}+v_{t}
$$

where $\beta_{1}$ is the estimate of the tax elasticity $(\varepsilon), T^{*}$ and $B^{*}$ are estimated using the HodrickPrescott (HP) filter for each tax (VAT, CIT, PIT, and SC), and CONTROLS is a vector of dummy variables to control for changes in the corresponding tax systems (including changes in statutory rates, exemptions, etc.).

16. One drawback of equation (2) is its reliance on the potential tax and tax base estimates obtained through the HP filter. The limitations of HP filter as a tool for disentangling the trend and cyclical fluctuations in emerging markets featuring short time series and frequent structural changes have been documented widely (e.g., De Masi, 1997). 
Therefore, one could estimate equation (2) using differences of $\mathrm{T}$ and $\mathrm{B}$, instead of their deviations from potential, to avoid relying on HP filter results: ${ }^{3}$

$$
\Delta \ln \left(T_{t}\right)=\beta_{0}+\beta_{1} * \Delta \ln \left(B_{t}\right)+\beta_{2} * \operatorname{CONTROLS}_{t}+\varepsilon_{t}
$$

17. Rolling window regression methods are used to capture the time variation in tax elasticities from equation (3). A fixed moving window of 28 quarters ( 7 years) is used in each estimation. Given the seasonal volatility of the series, year-on-year percentage changes are used for both $T_{t}$ and $B_{t}$. The obtained elasticity estimates together with their upper and lower bounds (computed as \pm 2 s.d. around coefficient estimates) are plotted to assess both the dynamics and significance of elasticities.

\section{Rolling window regressions confirm the time varying nature of tax elasticities, but the extent of variation differs across taxes:}

- The VAT elasticity has ranged between 0.5 and 1.5 . In line with the prima facie evidence, the elasticity increased at the onset of the downturn, which was not a positive development given that the bases were contracting sharply. In the recovery phase, the elasticity is returning to its pre-recession level but remains above 1 fueling the recent recovery in tax collections.

- The PIT elasticity ranges between 0.9 and 1.4. It was on an upward trend between $2006-08$, then slightly declined during the recession, and is currently rebounding to its pre-recession level. The elasticity has stayed above unity in most part of the sample, in line with the progressivity of this tax.

- The CIT elasticity ranges between 1 and 4 (the widest variation among taxes). It was on a declining path during the recession, but stabilized with the recent recovery. The wider variation of CIT elasticity compared to the one for other taxes can be explained by the relatively more uneven schedule of CIT payments within the year.

- The excise duty elasticity ranges between 0 and 1 . Similar to PIT, it is currently rebounding. This may indicate the progress made by the authorities to counteract crossborder smuggling of fuel and cigarettes, which became particularly prominent in the wake of the recession.

\footnotetext{
${ }^{3}$ Equation (3) can be derived from equation (2) by assuming constant growth rates in $B_{t}{ }^{*}$ and $T_{t}{ }^{*}$. For the estimation purposes, we take y-o-y differences to account for the seasonality effects.
} 
Time-Varying Elasticities from Rolling Regressions

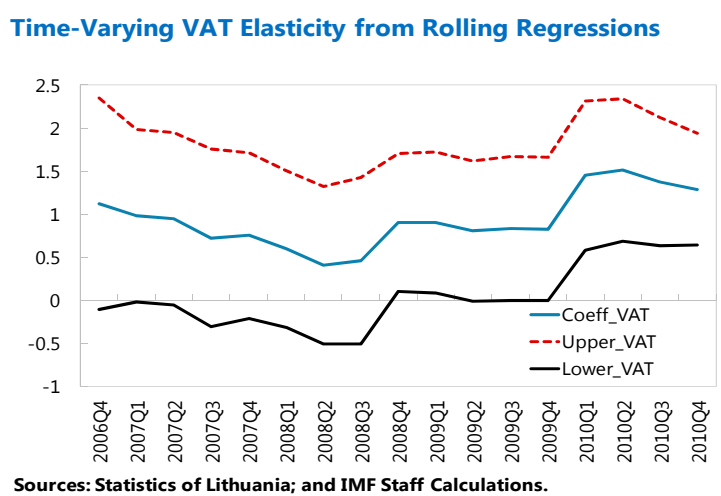

Time-Varying PIT Elasticity from Rolling Regressions

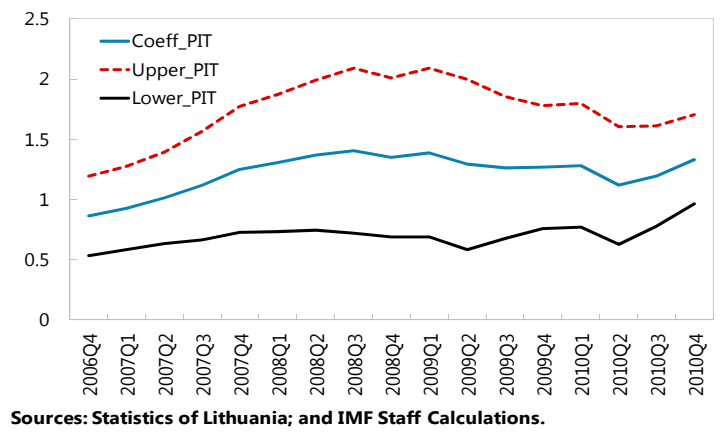

Time-Varying CIT Elasticity from Rolling Regressions

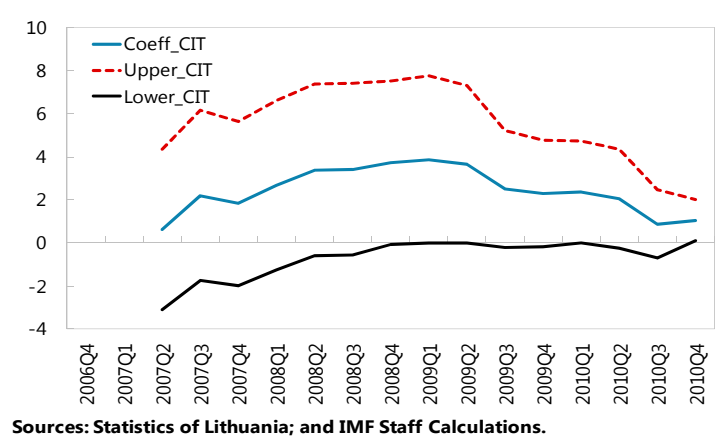

Time-Varying PIT Elasticity from Rolling Regressions

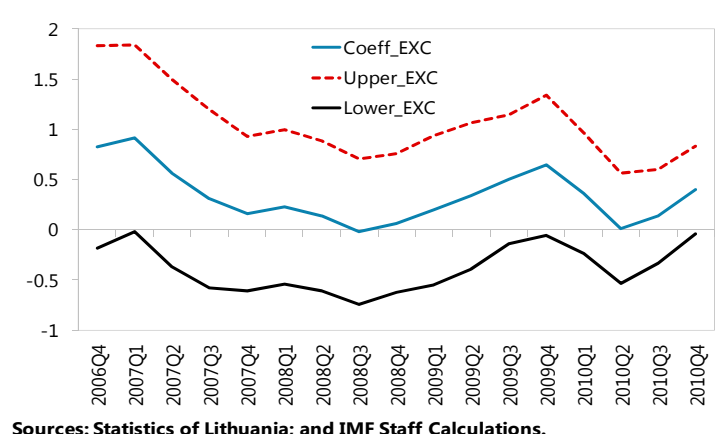

Note: Reported are time-varying elasticities from equation (3) using a moving window of 28 quarters (7 years). The following tax bases are used: wage bill (PIT), (lagged) operating surplus (CIT), personal consumption (VAT), and GDP (excise duty).

\section{Panel data regressions}

\section{We apply the pooled mean group (PMG) estimator of Pesaran et al. (1999) to} analyze the VAT tax elasticities in a panel of ten new EU member countries. The advantage of the PMG is that it provides an estimate of long-run tax elasticities and allows assessing the deviation of tax revenues from their long-run equilibrium implied by these elasticities. The empirical specification takes the following form:

$$
\Delta \ln \left(T_{i t}\right)=\phi_{i}\left[\ln (T)_{i t-1}-\beta_{0}-\beta_{1} \ln \left(B_{i t-1}\right)\right]+\delta_{i} \Delta \ln \left(B_{i t}\right)+\alpha_{i}+\varepsilon_{i t}
$$

where $\beta_{1}$ is the (pooled) long-run tax elasticity coefficient, $\phi_{i}$ is the (country-specific) speed of adjustment to the long-run equilibrium, $\delta_{i}$ is the (country-specific) short-run adjustment coefficient, $\alpha_{i}$ is the country fixed effect, and $\varepsilon_{i t}$ is the i.i.d. error term. We estimate specification (4) using VAT revenues adjusted for the impact of changes in statutory rates (T) 
and personal consumption (B). The dynamics of the deviations from long-run equilibrium (the term in square brackets) during the recent recession would help to shed light on the cyclicality of tax revenues in Lithuania. In addition, the difference between current tax revenues and their long-run equilibrium at the end of the sample (if negative) would help to assess the potential for further VAT revenue improvements in Lithuania.

\section{The PMG estimations produce strongly significant coefficients that are}

consistent with the economic rationale. The long-run tax elasticity coefficient is close to one in line with the neutral nature of the VAT explicitly assumed in previous work (see, e.g., Girouard and Andre, 1995). The speed of adjustment to the LR equilibrium is negative and significant, suggesting that about 10 percent of the deviation from the long-run equilibrium is adjusted within a quarter (column 1). Both results hold when real VAT and personal consumption are used in the estimations (column 2). The elasticity is slightly higher, but insignificantly different from one, when using annual data (columns 3 and 4). The speed of adjustment in the annual regressions suggests that about 60 percent of the deviation from the long-run equilibrium is adjusted within a year.

PMG Estimation Results

\begin{tabular}{|c|c|c|c|c|}
\hline \multirow[t]{2}{*}{ Model } & \multicolumn{2}{|c|}{ Quarterly data } & \multicolumn{2}{|c|}{ Annual data } \\
\hline & $\begin{array}{c}\text { Nominal } \\
(1)\end{array}$ & $\begin{array}{l}\text { Real } \\
(2)\end{array}$ & $\begin{array}{c}\text { Nominal } \\
(3)\end{array}$ & $\begin{array}{l}\text { Real } \\
\text { (4) }\end{array}$ \\
\hline \multicolumn{5}{|l|}{ Long-run relationship } \\
\hline Constant & $\begin{array}{c}-0.0296 * * * \\
{[-3.91]}\end{array}$ & $\begin{array}{l}-0.0274^{* * *} \\
{[-2.82]}\end{array}$ & $\begin{array}{c}-0.4264^{* * *} \\
{[-7.21]}\end{array}$ & $\begin{array}{l}-0.6626^{* * *} \\
{[-6.97]}\end{array}$ \\
\hline Private consumption (LR elasticity) & $\begin{array}{c}0.9809 * * * \\
{[27.94]}\end{array}$ & $\begin{array}{l}0.9976^{* * *} \\
{[12.17]}\end{array}$ & $\begin{array}{c}1.0273^{* * *} \\
{[39.95]}\end{array}$ & $\begin{array}{l}1.0746^{* * *} \\
{[20.90]}\end{array}$ \\
\hline \multicolumn{5}{|l|}{ Dynamics coefficients } \\
\hline Speed of adjustment & $\begin{array}{c}-0.1067^{* * *} \\
{[-6.42]}\end{array}$ & $\begin{array}{l}-0.0850 * * * \\
{[-4.07]}\end{array}$ & $\begin{array}{c}-0.6264^{* * *} \\
{[-6.09]}\end{array}$ & $\begin{array}{l}-0.6022^{* * *} \\
{[-5.68]}\end{array}$ \\
\hline Changes in private consumption & $\begin{array}{c}1.2120^{* * *} \\
{[8.96]}\end{array}$ & $\begin{array}{c}0.8372^{*} \\
{[1.94]}\end{array}$ & $\begin{array}{c}1.2865^{* * *} \\
{[10.87]}\end{array}$ & $\begin{array}{l}1.1882^{\star \star \star *} \\
{[6.09]}\end{array}$ \\
\hline Number of obs. & 470 & 470 & 110 & 110 \\
\hline Hausman test, $\mathrm{p}$-value (PMG versus $M G$ ) & 0.5783 & 0.3628 & 0.2076 & 0.3941 \\
\hline Hausman test, $\mathrm{p}$-value (PMG versus FE) & 0.9598 & 0.9746 & 0.9504 & 0.9645 \\
\hline
\end{tabular}

\section{Deviations of VAT revenues from their long-run equilibrium in Lithuania are}

closely related to the economic cycle. The deviations were positive during the pre-recession boom period (2006-08), but turned negative during the recession (2009-10). In more recent quarters, tax collections have exhibited a tendency of rebounding to the long-run equilibrium on the back of the ongoing recovery, but still remain about five percent below the equilibrium. The relationship between the economic cycle and the revenue gap was different in the pre-2006 period. In particular, the revenue gap was positive in end-1999-2000 when the economy was still suffering from the Russian crisis spillovers. This result can be explained by the composition effect: the positive contribution of the private consumption to the GDP growth in 1999-2000 (3.2 ppt on average), which has consistently exceeded the real GDP growth (2.1 ppt on average). In fact, private consumption was the only component 
positively contributing to GDP growth in 1999, which has fueled VAT collections. This is in contrast to 2003-04, when VAT revenue gap was negative. During this period, the contribution of private consumption ( $7 \mathrm{ppt}$ on average) to growth was lower than the output growth itself (8.8 ppt on average).

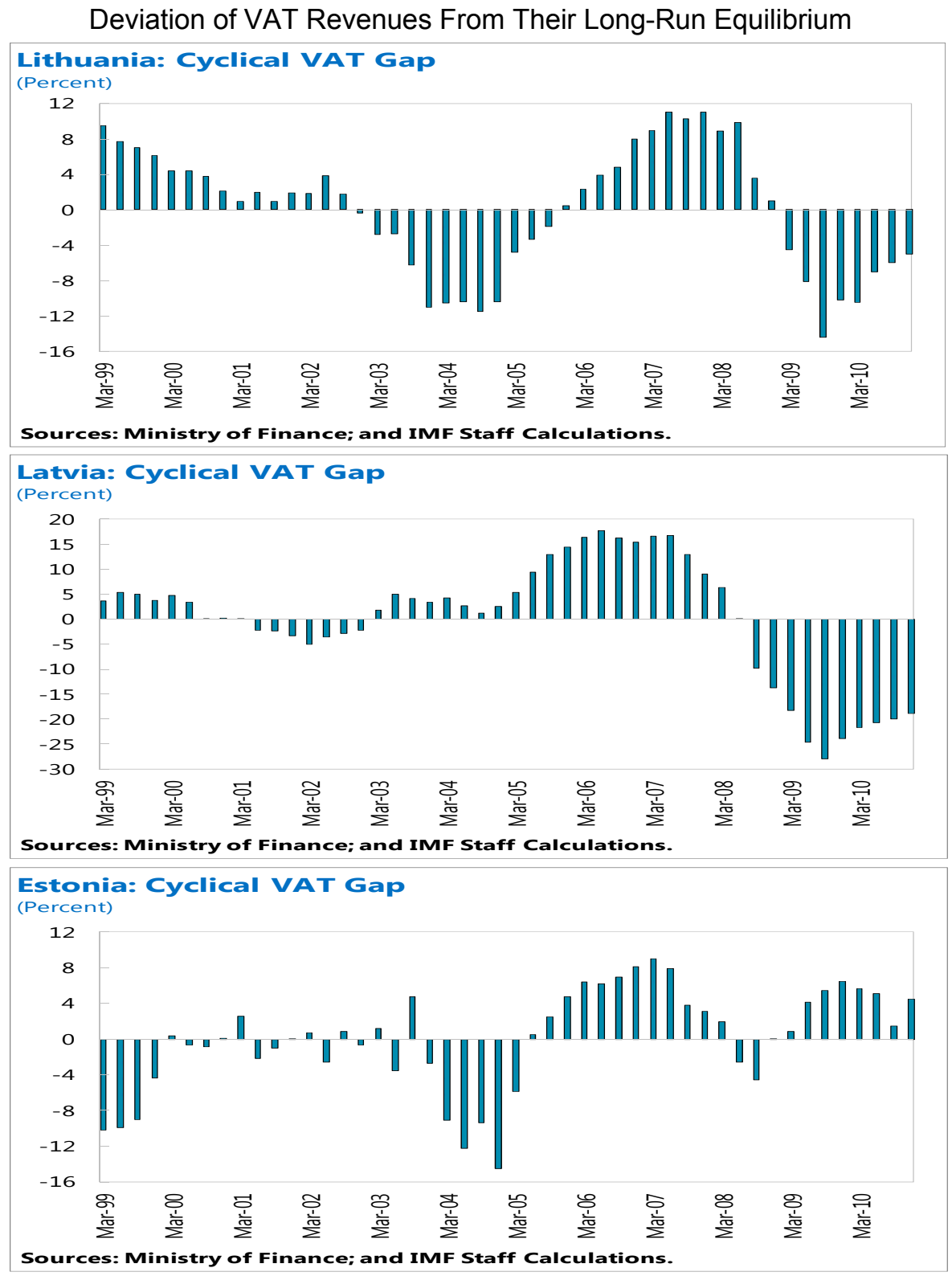

\section{Comparison of VAT revenue gaps in Lithuania relative to other two Baltic} countries reveals some similarities. First, the revenue gap was positive in all Baltic countries during the 2006-08 period, when all three countries were benefitting from the tailwinds and the booming economic environment. Next, the revenue gap turned negative in all three countries following the bust. However, while in Estonia the revenue gap has returned back to positive at the beginning of 2009, the gap has stayed negative in both Latvia 
and Lithuania. The relatively better performance of revenues in Estonia can be explained by tighter revenue administration efforts as evidenced by outstanding C-efficiency scores (see Figure 3). Among three Baltics countries, Latvia has experienced the largest revenue drop during the recession, resulting in a negative revenue gap of about 20 percent at end-2010, which is four times larger than the 5 percent negative gap obtained for Lithuania.

\section{F. Conclusions}

\section{The above analysis provides empirical evidence on the variability of tax}

elasticities in Lithuania. The deviation of short-run tax elasticities from their long-run counterparts can be driven by the composition effects in tax bases and cyclical movements in tax compliance. The direction of the variation differs across taxes, with most elasticities being flat during the recession and rebounding with the recent economic recovery. The panel regressions suggest that the most recent VAT collections in Lithuania are below their long-run equilibrium level by about 5 percent, implying that there is room for further improvement in VAT revenues in coming months.

24. The variability of tax elasticities has important policy implications. Deviations of tax elasticities from their long-run level should be taken into account when making shortterm tax revenue projections. The deviation of short-term tax elasticities from their long-run level can be especially pronounced in new EU member countries with tax systems heavily relying on taxing flows (rather than stocks), which are more volatile compared to the EU average. For instance, long-run VAT elasticities should be adjusted above unity during the periods of rapid economic expansions and contractions. The extent of adjustment should vary across taxes, in line with the extent of their responsiveness to the business cycle. 


\section{References}

Agha, A, and Haughton, J., 1996, "Designing VAT Systems: Some Efficiency Considerations," Review of Economics and Statistics, 78 (3), pp. 303-08.

Aizenman, J., and Jinjarak, Y., 2008, "The Collection Efficiency of the Value Added Tax: Theory and International Evidence," The Journal of International Trade \& Economic Development, 17 (3) pp. 391-410.

Aydin, B., 2010, "Cyclicality of Revenue and Structural Balances in South Africa," IMF Working Paper 10/216.

Bornhorst, and others, 2011, "When and How to Adjust Beyond the Business Cycle? A. Guide to Structural Fiscal Balances," Technical Guidance Note, Fiscal Affairs Department (Washington: International Monetary Fund).

Bouthevillain, and others, 2001, "Cyclically Adjusted Budget Balances: An Alternative Approach," ECB Working Paper No. 77.

Congressional Budget Office, 2009, "Measuring the Effects of the Business Cycle on the Federal Budget," (Washington: Congressional Budget Office).

De Masi, P., 2007, "IMF Estimates of Potential Output: Theory and practice," IMF Working Paper WP/97/177.

De Mello, L., 2009, "Avoiding the Value-added Tax: Theory and Cross-country Evidence," Public Finance Review, 37(1): pp. 27-46.

Fedelino, A., Ivanova, A., and Horton, M., 2009, "Cyclically-Adjusted Balances and Automatic Fiscal Stabilizers: Some Computational and Interpretational Issues," IMF Technical Notes and Manuals TNM/09/05.

Girouard, N., and André, C., 2005, "Measuring Cyclically-adjusted Budget Balances for OECD Countries," OECD Economics Department Working Paper No. 434.

Sancak, C., Velloso, R., and Xing, J., 2010, “Tax Revenue Response to the Business Cycle,” IMF Working Paper WP/10/71.

Pesaran, H., Shin, Y., and Smith, R., 1999, "Pooled Mean Group Estimation of Dynamic Heterogeneous Panels," Journal of the American Statistical Association, 94: pp. 621-34. 


\section{Appendix I. Data}

\section{Data used in the estimations}

We use quarterly data on taxes and their bases for the 1999-2010 period. Data on VAT, PIT, CIT, and EX for Lithuania, as well as changes in tax systems (based on which control dummies are generated), are obtained from the Ministry of Finance. Information on tax bases, including GDP, personal consumption, wage bill, operating surplus, is taken from Statistics Lithuania. We also use a panel data on VAT revenues and personal consumption for ten new EU member countries from the Eurostat. The new EU member countries used in the analysis are: Bulgaria, Czech Republic, Estonia, Latvia, Lithuania, Hungary, Poland, Romania, Slovenia, and Slovakia.

The pooled mean group (PMG) estimator (Pesaran et al., 1999)

The PMG estimator is a panel data version of the error-correction model. It imposes a homogeneity restriction on the long-run relationship between VAT and its base, while allowing for the short-run effects to vary across countries. The PMG takes a middle ground between the two alternative estimation extremes:

- the fixed effects (FE) estimator, which imposes the homogeneity restriction on both longrun and short-run slope coefficients;

- the mean-group (MG) estimator, which assumes that both long-run and short-run coefficients vary across countries.

The PMG specification can be tested against the MG and FE models using the Hausman test. The Hausman test does not reject the hypothesis of poolability of the longrun coefficients in both quarterly and annual regressions, favoring the PMG specification against the alternative MG specification. The evidence in favor of the PMG specification is even stronger when the FE specification is considered as an alternative. Taken together, these results suggest that the long-run elasticity of unity for VAT holds for all new EU member countries. However, VAT revenue collections can deviate from their long-run equilibrium at any particular time period and economic cycles can exacerbate these deviations. 